\title{
Development of Cluster-Based Energy Management Scheme for Residential Usages in the Smart Grid Community
}

\author{
Md Mamun Ur Rashid ${ }^{1,2}$, Fabrizio Granelli ${ }^{1}\left(\mathbb{D}\right.$, Md. Alamgir Hossain ${ }^{3,4, *}$, Md. Shafiul Alam ${ }^{5}$, \\ Fahad Saleh Al-Ismail ${ }^{5}$ and Rakibuzzaman Shah ${ }^{6}$ D \\ 1 Department of Information Engineering and Computer Science, University of Trento, 38122 Trento, Italy; \\ mdmamunur.rashid@alumni.unitn.it or mamun@niter.edu.bd (M.M.U.R.); granelli@disi.unitn.it (F.G.) \\ 2 Department of Electrical and Electronic Engineering, National Institute of Textile Engineering and \\ Research (NITER), Dhaka 1350, Bangladesh \\ 3 Capability Systems Centre, School of Engineering \& Information Technology, \\ University of New South Wales-Canberra, Campbell, ACT 2612, Australia \\ 4 Department of Electrical and Electronic Engineering, Dhaka University of Engineering and \\ Technology (DUET), Gazipur 1707, Bangladesh \\ 5 K.A.CARE Energy Research \& Innovation Center, King Fahd University of Petroleum \& Minerals(KFUPM), \\ Dhahran 31261, Saudi Arabia; mdshafiul.alam@kfupm.edu.sa (M.S.A.); fsalismail@kfupm.edu.sa (F.S.A.-I.) \\ 6 School of Engineering, Information Technology and Physical Sciences, Federation University, \\ Ballarat 3350, Australia; m.shah@federation.edu.au \\ * Correspondence: Md.Hossain6@unsw.edu.au or alamgir_duet@hotmail.com
}

Received: 29 July 2020; Accepted: 1 September 2020; Published: 7 September 2020

\begin{abstract}
Several efforts have been taken to promote clean energy towards a sustainable and green economy. Existing sources of electricity present some complications concerning consumers, utility owners, and the environment. Utility operators encourage household applicants to employ residential energy management (REM) systems. Renewable energy sources (RESs), energy storage systems (ESS), and optimal energy allocation strategies are used to resolve these difficulties. In this paper, the development of a cluster-based energy management scheme for residential consumers of a smart grid community is proposed to reduce energy use and monetary cost. Normally, residential consumers deal with household appliances with various operating time slots depending on consumer preferences. A simulator is designed and developed using C++ software to resolve the residential consumer's REM problem. The benefits of the RESs, ESS, and optimal energy allocation techniques are analyzed by taking in account three different scenarios. Extensive case studies are carried out to validate the effectiveness of the proposed cluster-based energy management scheme. It is demonstrated that the proposed method can save energy and costs up to $45 \%$ and $56 \%$ compared to the existing methods.
\end{abstract}

Keywords: demand-side management (DSM); energy storage systems (ESS); residential energy management (REM); renewable energy sources (RESs); smart grid; smart meter; self-satisfied power demand

\section{Introduction}

The rising energy demands and limited supply capacity of generators could stimulate severe electricity price spikes. On the other hand, residential applicants who have been receiving energy with fixed charges are now capable of controlling their load patterns in response to real-time prices [1]. An efficient energy management scheme is a pivotal part of the smart grid infrastructure that integrates 
the effective execution of demand-side management (DSM) and the flexible operation of energy efficient controllable home appliances [2,3]. DSM inspires customer portals for optimal energy usage, real-time pricing, and energy consumption monitoring by the dual flow of electricity and communications [4]. In recent times, effective means of reducing the gradually growing energy requirement and promotion of clean energy have gained paramount importance around the world. Traditional power generation methods rely heavily on fossil fuels, which contributes to massive greenhouse gas emissions. In order to meet the increasing power demand and promote clean energy generation with zero emissions, researchers have defined unique pathways of generating electricity such as sustainable and renewable energy resources (SRERs) [5]. However, the distribution of renewable energy sources (RESs) significantly increases power system complexity [6]. The current power system is not capable of maintaining its stability with high penetration of uncontrollable RESs and distributed generation (DG). In this context, one of the present solutions is the transformation of the existing power grid into the smart grid (SG) with advanced information and communication technologies (ICTs) [7]. Cutting-edge ICTs not only enable SG to combine the DG and RESs but also improve the reliability and stability of the power system infrastructure. Smart meters (SMs), smart home appliances, RESs, and energy storage systems (ESS) are the significant resources of smart grid technology. The main features of the SG are the control of power generation, transmission, and distribution through advanced ICTs [8].

DSM is an integrated part of a smart grid which allows flexible operation for the power system to improve system reliability. There are key factors that make smart grid superior over traditional power grids. Firstly, a two-way flow of power and communication via wireless technologies such as Wi-Fi, ZigBee, WiMAX, etc. Secondly, advanced metering infrastructure (AMI) via a power data aggregator and management unit (PDAMU). In SG, dual communication keeps the home users well informed regarding different utility parameters such as electricity prices, distribution network up-gradation scheduling, natural disasters, or equipment failures. However, the smart grid plays a crucial role to enable the operator to monitor operation activities and analyze real-time energy consumption and pricing [9].

An automatic home energy management scheme (HEMS) can save energy and cost for the residential users and currently it is an integral part of the concept of smart grids and smart cities [10]. Single or multiple groups of smart homes can act as a smart city. A little awareness of the home user's energy consumption scheduling schemes is required to know the benefits from different aspects [11]. The role of SG is not only to integrate renewable energy resources but also to incorporate residential consumers into DSM activities [12]. The common objectives of the DSM in the smart grid are the reduction in the electricity price and minimization of energy use in peak hours [13]. However, the current literature study shows that there is a gap in developing an efficient cluster-based energy management scheme which can reduce consumers' energy prices with a higher level of customer satisfaction. To fill up these gaps, an efficient energy allocation algorithm (EAA) for a residence energy management (REM) system is proposed in this study.

The utility costs for residential consumers can be saved by the support of RESs and ESS [14] in smart grid architecture. The work presented in [15] outlined a detailed review of the current progression in the HEM system, challenges in appliance scheduling, and energy optimization in the smart grid community. In addition, the incorporation of RESs into households and their effects on utility tariffs have not been addressed properly. Researchers [16] demonstrated the necessity and planning of energy management in smart cities based on generation, transportation, storage, and end-user energy demand. However, the dynamic pricing of the electricity market of residential appliances for energy consumption have not been discussed. Authors [17] give insights regarding the ways and manners that facilitate the integration of RESs and distribution grid (DG) in the SG and the concept of smart cities has been comprehensively addressed. However, the integration of RESs and ESS for the residential applicants and their role in DSM programs have been ignored. The authors in [18] presented a framework of methods and models for accounting the uncertainties due to distributed wind and solar photovoltaic power generation beyond the planning period in an AC multi-period optimal power flow 
(MPOPF) model for distribution systems with energy storage. In addition, the authors in [19] focused on the model predictive control (MPC)-based energy scheduling of a smart microgrid equipped with controllable (i.e., with flexible and programmable operation) and non-controllable (i.e., with fixed power profile) electrical appliances, as well as photovoltaic (PV) panels, and a battery energy storage system (BESS) that allows for storing a surplus of energy for later use. However, two important issues, such as cluster-based energy management and self-satisfied power demand, were not considered. The authors in [20] proposed a decision technique of an optimal reference schedule for distributed generators (DGs), battery energy storage system (BESS), and tap changing transformers to reduce line losses in the distribution system. However, energy and cost minimization considering self-satisfied power demand was not taken in to account. The authors in [21] reviewed the energy management approaches in smart environments and extensively reviewed peak load shaving and demand response. The authors in [22] outlined a brief overview on the architecture and functional modules of smart home energy management system (HEMS). The researchers in [23] presented a versatile convex programming (CP)-based demand response optimization framework for the automatic load management of various household appliances in a smart home. The authors in [24] suggested informing the community energy management system (CEMS) about the adjustable power in addition to the surplus and shortage information. However, a cluster-based energy management scheme has not been addressed to improve the efficiency and reduce the cost of residential users.

The authors in [14] outlined a comprehensive overview of evaluating trends in smart homes and smart grids and examined the effectiveness of numerous communication technologies such as $\mathrm{Wi}-\mathrm{Fi}$, ZigBee, Z-Wave, and wired protocols. The researchers also figured out the benefits and drawbacks of existing technologies, and products available in the market. Moreover, the role and future trends regarding communication technologies and their barriers, challenges, and, benefits in the smart grid and smart homes were also discussed. However, this work did not take into account the cluster-based energy management and energy allocation algorithm (EAA) in the smart grid framework. The authors in $[15,16]$ demonstrated a household energy supervising system interfaced with a data logger unit to measure and record the electricity generation and demand patterns. In addition, RESs, ESS, and self-satisfied power demand were not considered to generate an alternative source of energy and storage facilities while peak demand appears.

While several works dealt with the advanced methods, these methods are not typically adopted by industry due to the reliability and security issues of a power system. Therefore, to improve the cluster-based energy management system for residential consumers, this research develops an efficient energy management system using commercial software, $\mathrm{C}++$, considering RESs, and an ESS in a smart grid framework. The proposed residence energy management (REM) system offers low energy costs compared to the existing methods with higher customer satisfaction. The contributions of this paper are listed as follows:

- Efficient simulation techniques are developed to avert the peak load of the established model.

- The proposed model enables an energy allocation strategy in a community to be assessed sequentially.

- An advanced smart metering architecture is integrated into the proposed smart grid model to acquire real-time pricing and remote monitoring of energy consumption.

- Mathematical modeling is developed to facilitate extensive analysis.

- Self-satisfied power demand is achieved using energy allocation algorithm (EAA).

- Optimal energy and cost saving are achieved and outlined properly.

The rest of the paper is organized as follows: Section 2 discusses the problem description and smart grid architecture including advanced smart metering infrastructure. Section 3 explains the system model including system components, such as a solar generator, wind generator, energy storage systems, loads and utility grid, mathematical modeling of a smart home, and the proposed algorithms are also presented in this section. Analysis of the results and graphical representation of simulation 
results are elaborated in Section 4. Finally, the conclusion with some future research directions is depicted in Section 5.

\section{Problem Description}

This section outlines the proposed smart grid architecture and its intelligent features with the application of smart metering infrastructure in the smart grid framework.

The proposed cluster-based smart grid architecture illustrated in Figure 1 consists of several energy clusters to identify residential consumers rapidly to reduce operation time. The rapid growth in household appliances significantly increases the power demand for residential consumers. Nowadays, most of the electricity consumption is met by fossil fuel-based generation which severely affects the environment by emitting greenhouse gas [17]. According to the international standard, each country must put a cap on their carbon emissions to save the environment. Thus, researchers are working hard to figure out new means of power generation. In this context, the integration of RESs and ESS is found to be one of the most cost-effective and environment-friendly solutions $[17,25,26]$. Moreover, the existing power system is already vulnerable due to the large application of non-linear loads [27].

The proposed smart grid architecture is designed and developed considering renewable energy sources (RESs) and energy storage systems (ESS). The smart grid community contains a group of residential consumers with smart meters, equipped with a wireless interface. All home appliances are connected via wireless connection with smart meters to monitor real-time energy consumption and pricing. If any residential consumer requires more power than the usual consumption, then the consumer sends the extra power demand signal to the power data aggregator and management unit (PDAMU) in real time. The energy community is divided into three energy clusters, namely clusters A, B, and C. Each cluster has independent energy storage to support energy while renewable energy generation and utility supply is off. In addition, when all forms of supply, including renewable energy, cluster storage, and power-sharing, are unable to provide power, then the utility company assists the power supply and the users have to pay for this energy demand as an extra cost.

Normally, household load consists of lights, fans, televisions, computers, refrigerators, space heaters, washing machines, dishwashers, and so on. Each premise has an energy meter to record utility consumption and convey back the collected energy data to the utility operator. The utility system reports back the power consumption bills to the users for a certain period and the user pays for the consumption. This structure does not allow customers to play an important role in the energy market. Thus, the customers are unable to reduce energy costs by selling their surplus energy if they have any rooftop PV solar or energy storage system (ESS).

Most of the residential consumers face some difficulties during energy reception from the utility operator such as unstable voltage supply, increased power losses in the service domain, peak load tariff, unexpected system maintenance, and so on. To minimize these drawbacks, the residence energy management (REM) system is an optimal solution. To address these issues, a cluster-based REM system is proposed to provide an economic and long-term solution. In this research, a cluster-based energy management scheme is applied to schedule household appliances based on peak, off-peak and mid-peak demands to reduce utility charges. If any particular consumer has an energy demand, PDAMU manages the user's requested energy demand based on request priorities. Energy clustering is an efficient technique to manage energy demand as fast as possible by keeping individual energy use IDs. Each residence has a unique energy use ID to keep track of PDAMU and trace them while the energy crisis appears. For better understanding, this can be outlined as Rony-A or Rony-B or Rony-C. Here, Rony is the consumer name and $\mathrm{A}, \mathrm{B}$, and $\mathrm{C}$ are the energy clusters.

Smart meters (SM) are one of the vital parts of the smart grid architecture which is employed to track energy use and to facilitate information exchange between the consumers and utility companies [28]. A smart home provides an interface between consumers and appliances to track consumption patterns and take essential optimized decisions [29]. The smart meters connect residential appliances 
and facilitate the users to shift from peak hours to off-peak hours [30]. The voltage, frequency, and power factors are key measurements which are utilized in smart meters to monitor real time energy consumption rates.

A smart metering system consists of measuring devices and communication links as visualized in Figure 2. The time-of-use pricing, DSM, and automatic meter reading framework are the key features of the smart meter architecture. The home area network (HAN) is deployed within the residential units for linking several electrical appliances to the smart meter [31]. PDAMU, the main controlling unit of the smart grid architecture, which is installed in a secondary sub-station in the distribution network, allows the smart meter to send and receive pricing information, the real-time energy consumption, and extra power demand. The several sub-data centers in PDAMU update the smart meter data via wireless communication links. The consumer extra power demand is sent to PDAMU using the smart meters through the communication links. Then, the PDAMU initiates the process to evaluate the battery state of charge of all users within the coverage area to meet this extra power demand [32]. In this study, the PDAMU evaluation process and extra power demand are managed with the efficient energy allocation algorithm (EAA) which considers both users' extra power and the supply from the utility company.

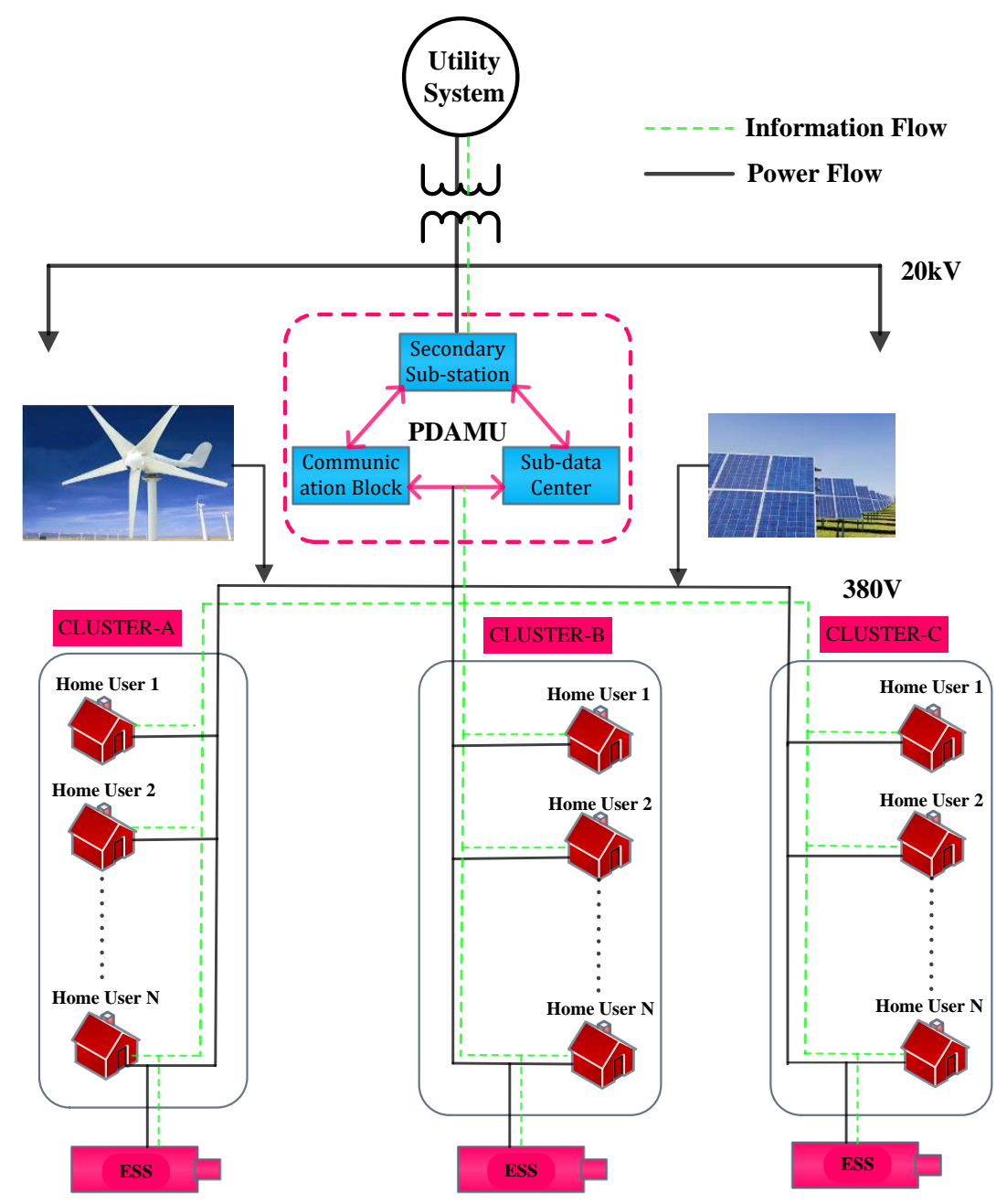

Figure 1. The cluster-based smart grid architecture. 


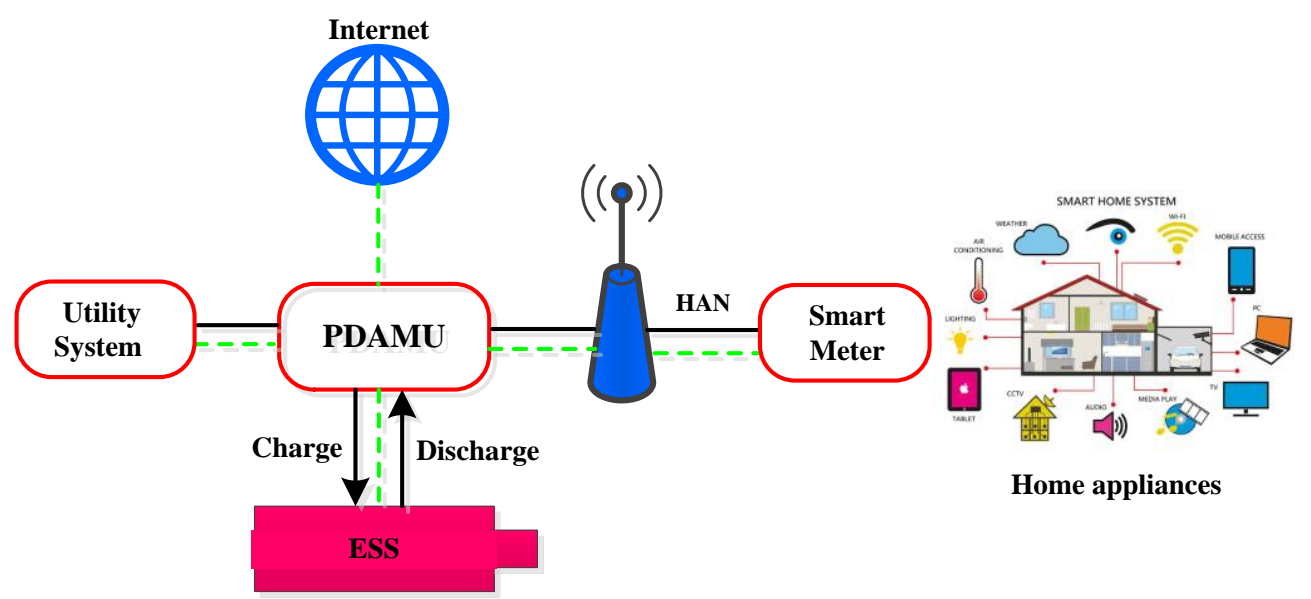

Figure 2. Advanced smart metering architecture in the smart grid environment.

The total hourly and daily basis energy consumption with the cost is evaluated using a clustering-based energy management scheme for residential prosumers. In general, the peak load hours' energy price is higher than that of the off-peak load hours, which is set by the utility operator. In addition, mid-peak hours have a regular price which is between the price of off-peak hours and peak hours. To overcome the peak demand, RESs and ESS support the smart grid system as alternative sources of energy. If the RES's generation is not sufficient to meet the power demand, then communication is made with PDAMU for another source of energy. The requested power demand is managed by a forwarding message through the smart grid community and the users receive power according to the priority of the request. Any consumer shares individual battery power while they have at least $50 \%$ of his rated capacity due to self-sustainability.

\section{System Modeling and the Proposed Algorithm}

This section deals with system components for the cluster-based energy management scheme in the smart grid framework. Solar and wind generators, an energy storage system and a typical energy consumption profile for residential consumers are also considered. Furthermore, the home appliances considering peak-load, mid-peak, and off-peak loads and real-time electricity prices scenarios are modeled.

\subsection{Wind Generator}

Wind power is an alternative source of energy available around the globe with abundant features. It is the method of power generation by rotating turbine blades installed at an elevated height. However, the power generated from wind turbines is highly intermittent and stochastic. It is highly dependent on the available wind speed and significantly varies based on the installation height. Figure 3 below illustrates wind speed over a range of time. The following power-law equation is used to convert wind speed recorded by anemometer (installed at tower heights) and transfer them based on hub heights [33]:

$$
\frac{v}{v_{0}}=\left(\frac{h}{h_{0}}\right)^{\infty}
$$

In the equation above, $v_{0}$ and $v$ are the wind velocity at the hub height $h_{0}$ and $h$, respectively, and $\alpha$ is the power-law exponent which is a function of parameters [34]. The value of $\alpha$ is generally considered as $1 / 7$ for open space. The power generated by wind turbines is a function of wind velocity, 
and a piece-wise function relates the relationship between the wind speed and output power as follows [35]:

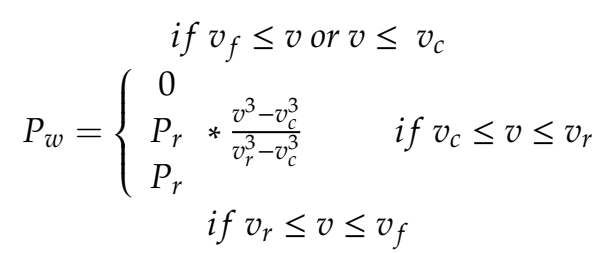

where $P_{r}$ and $v_{r}$ are the rated electrical power and rated wind speed, respectively, and $v, v_{c}$ and $v_{f}$ represent wind speed, cut-in wind speed, and cut-off wind speed, respectively. Turbine manufacturers define a cut-in and cut-off speed due to safety concerns. The wind generator does not produce any power beyond the cut-off wind speed. The total output power for a number of wind turbines can be expressed as follows [36]:

$$
P_{w T}=P_{w} \times N_{w}
$$

where $N_{w}$ is the number of wind generator.

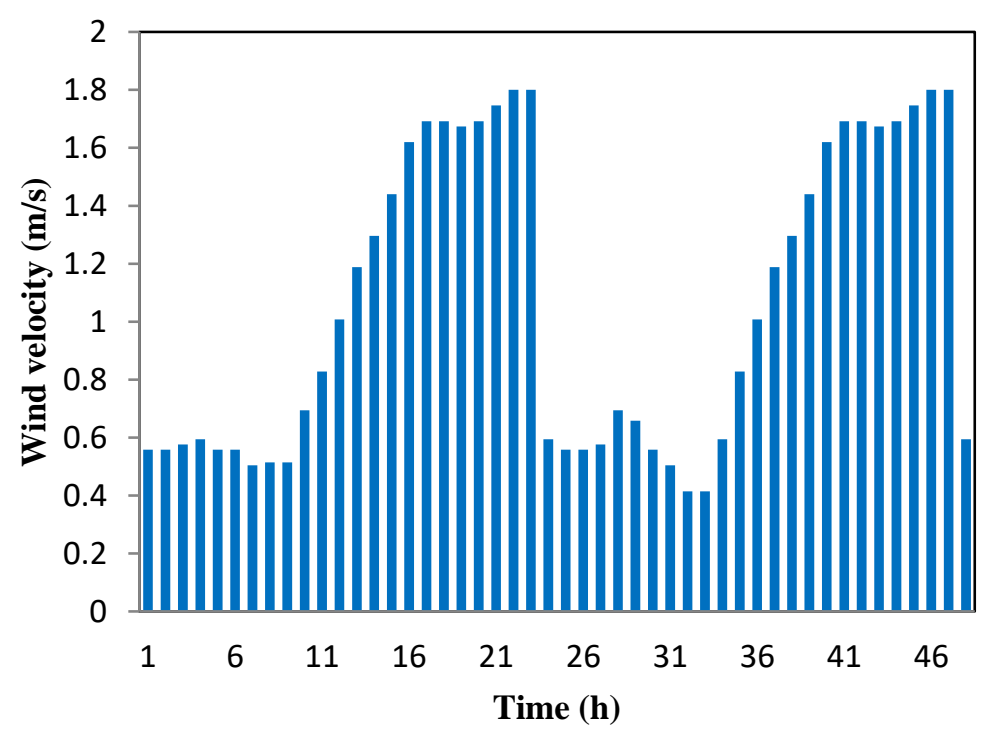

Figure 3. Predicted wind velocity over $48 \mathrm{~h}$ time horizon.

\subsection{Solar Generator}

Photovoltaic (PV) panels use sunlight to convert solar energy into usable DC electricity. The amount of PV power generated depends on the array size, solar radiance and solar insolation. Solar radiance relies emphatically on the surrounding climate and varies significantly, as depicted in Figure 4. The hourly pattern of solar irradiance as shown is used in this study for solar power generation and efficient cluster-based energy management development. To gain the maximum yield, PV panels are equipped with maximum power point tracking (MPPT) technology [37]. The performance of a PV system is assessed based on its output power. Output power depends on the size of the array and the overall efficiency of the installed PV system. On the other hand, during dark and cloudy weather and the winter season, the output power generation is significantly lower than sunny days and this is a great drawback of this system. PV power output as a function of solar irradiance and being operated at the MPPT mode is defined using the following equation:

$$
P_{s}=\eta_{s} * A * S I\left(1+\gamma\left(t_{0}-25\right)\right)
$$

In Equation (1) above, $\eta_{s}$ and $A$ are the overall system efficiency and area of PV panels respectively. $S I$ and $t_{0}$ denotes solar irradiation and surrounding air temperature, whereas $\gamma$ corresponds to the temperature coefficient of the maximum output power and is generally represented as a negative 
percentage per ${ }^{\circ} \mathrm{C}$ or $\mathrm{K}$. The value of $\gamma$ depends on the $\mathrm{PV}$ technology and manufacturing parameters, it is considered as $-0.005 /{ }^{\circ} \mathrm{C}$ for this study. The range of $\gamma$ for silicon cells is between 0.004 and 0.006 per ${ }^{\circ} \mathrm{C}$ [38]. For several solar generators, the total output power can be extracted as follows:

$$
P_{s T}=P_{s} \times N_{s}
$$

where $N_{S}$ is the number of solar generators.

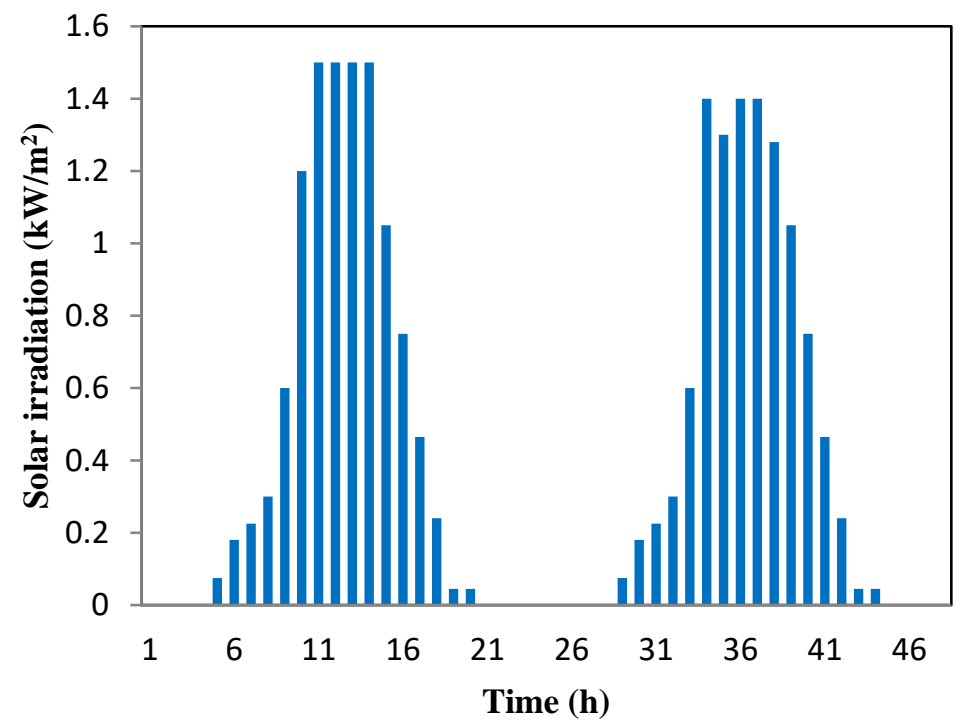

Figure 4. Predicted solar irradiation over a $48 \mathrm{~h}$ period.

\subsection{Energy Storage Systems}

The several energy storage methods, such as flywheel energy storage, compressed air energy storage, superconducting magnetic energy storage, supercapacitor, and battery, are extensively employed in the smart grid system. These energy storage methods have numerous features, including response times, storage abilities, and peak current competences, which are used in many applications with several time-units. In this study, electrochemical batteries are used due to their capabilities to store energy for a long time compared to supercapacitors and others. The ESS facilitates a reduction in energy imbalance, by charging and discharging, which stems from the intermittent nature of RESs. The charging and discharging of the battery can be understood by the equations below [25]:

$$
\begin{array}{cc}
B L(t)=B L(t-1)+\Delta t P_{c}(t) \eta_{c} & \text { if battery is charged } \\
B L(t)=B L(t-1)+\Delta t P_{d}(t) \eta_{d} & \text { if battery is discharged }
\end{array}
$$

Subject to the following battery constraints:

Power limits:

$$
P_{c, \max }>P_{c}>0 P_{d, \max }<P_{d}<0
$$

Battery energy level limits:

$$
B L_{\max }>B L(t)>B L_{\min }
$$

where $P_{c}(t)$ is the charging power, $P_{d}(t)$ is the discharging power, $t$ is the time, $B L(t)$ is the energy storage, $\Delta t$ is the time period, $\eta_{c}$ is the charging efficiency, and $\eta_{d}$ is the discharging efficiency.

\subsection{Loads and Utility Grid}

The load profiles of residential users are illustrated in Figures 5-7. Moreover, Figure 8 indicates related energy prices. The load patterns of peak-hours, mid-peak hours, and off-peak 
hours, as considered in this study, are illustrated separately. The maximum load is approximately $0.43 \mathrm{~kW}$ during peak-hours, the medium load is $0.42 \mathrm{~kW}$ during intermediate-hours and minimum load is $0.32 \mathrm{~kW}$ during off-peak-hours.

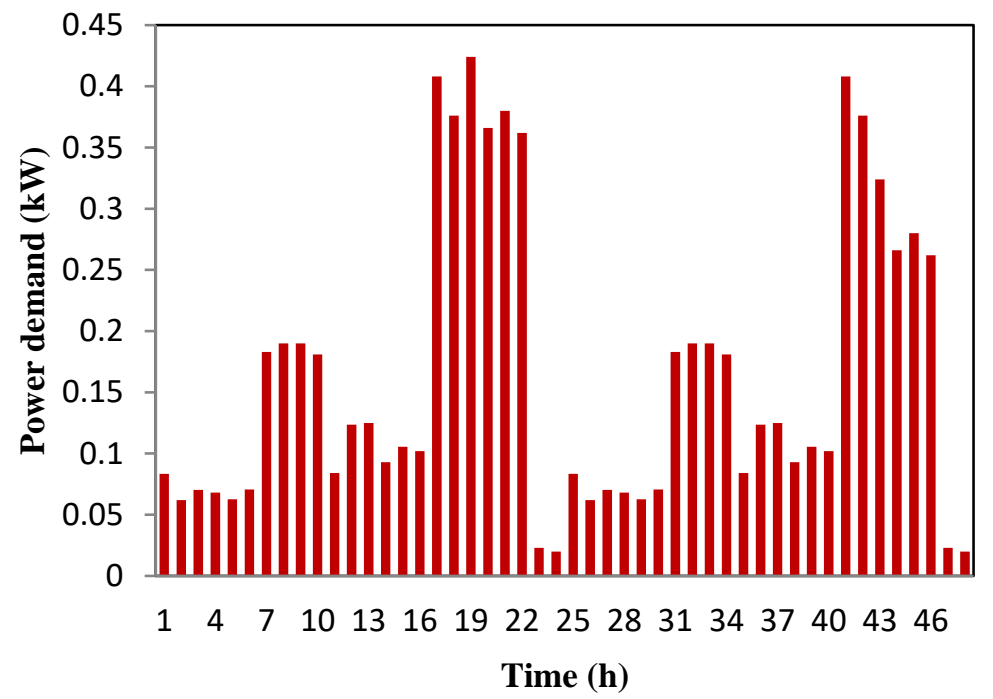

Figure 5. Predicted load profile of a house during peak-hours over a $48 \mathrm{~h}$ period.

The estimated loads can meet the primary home appliances such as washing machine, freezer, fans, lights, laptops, television, heater, dishwasher, microwave oven, and so on. Home user energy demand patterns fluctuate with time. Several measurement output values can shape the diverse energy demands for the individual consumers.

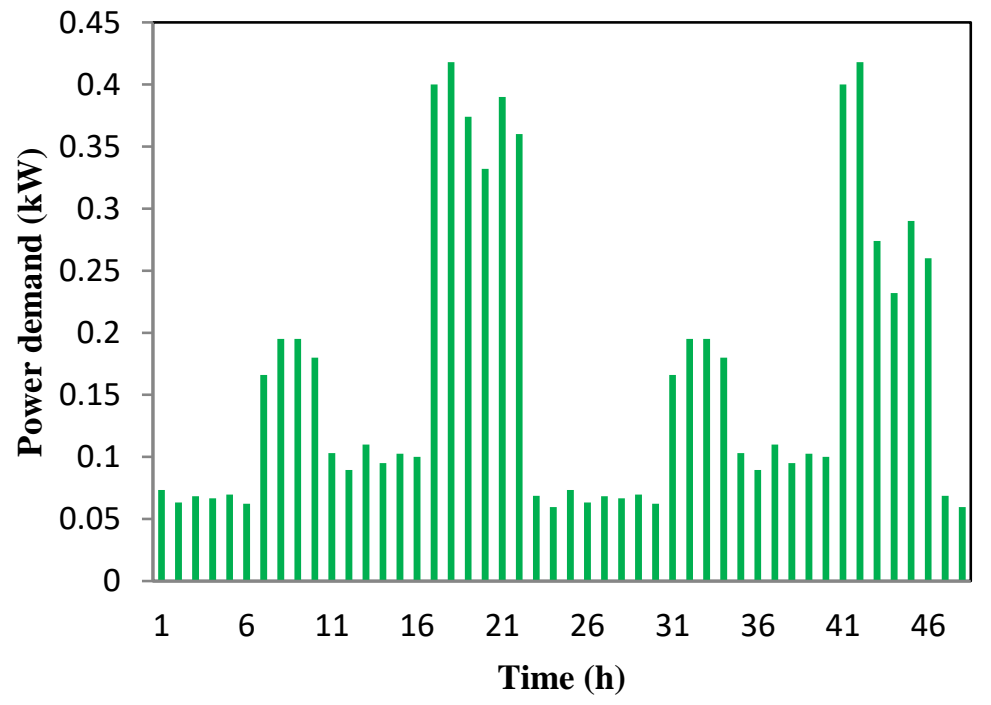

Figure 6. Predicted load profile of a house during mid-peak hours over a $48 \mathrm{~h}$ period.

Figure 8 indicates the real-time electricity prices for energy purchase per unit that is taken as a grid model in this study. These dynamic prices help electricity customers to schedule flexible loads, such as water heaters and washing machines. Electricity prices are generally announced an hour ahead from a distribution management company. A community smart grid that is connected to the main utility grid is investigated.

This study considers that the project is executed in an environment where building renewable energy plants is encouraged by the local government, for instance, in European countries, and the generated power can exchange to the utility grid without any transfer threshold. This process is 
due to insufficient power production, leading to low voltage outlines in the smart grid energy community. As a result, renewable energy owners can add more money to their utility business to help community inhabitants.

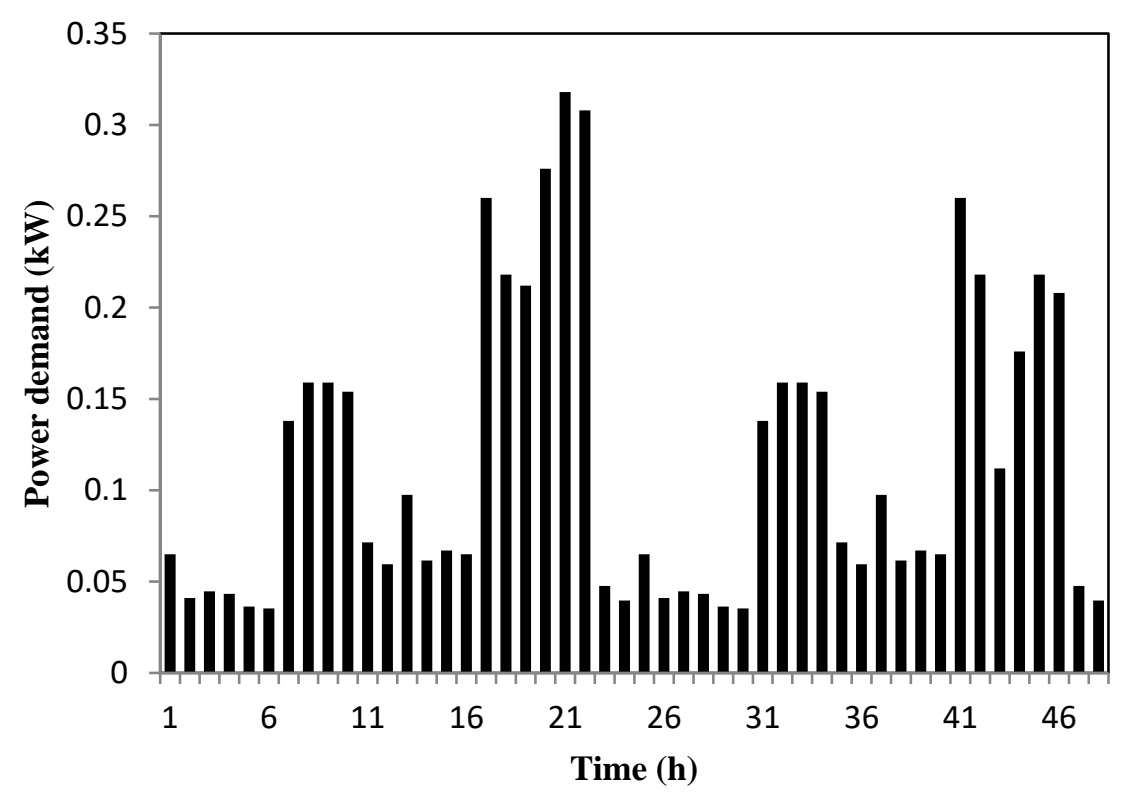

Figure 7. Predicted load profile of a house during off-peak hours over a $48 \mathrm{~h}$ period.

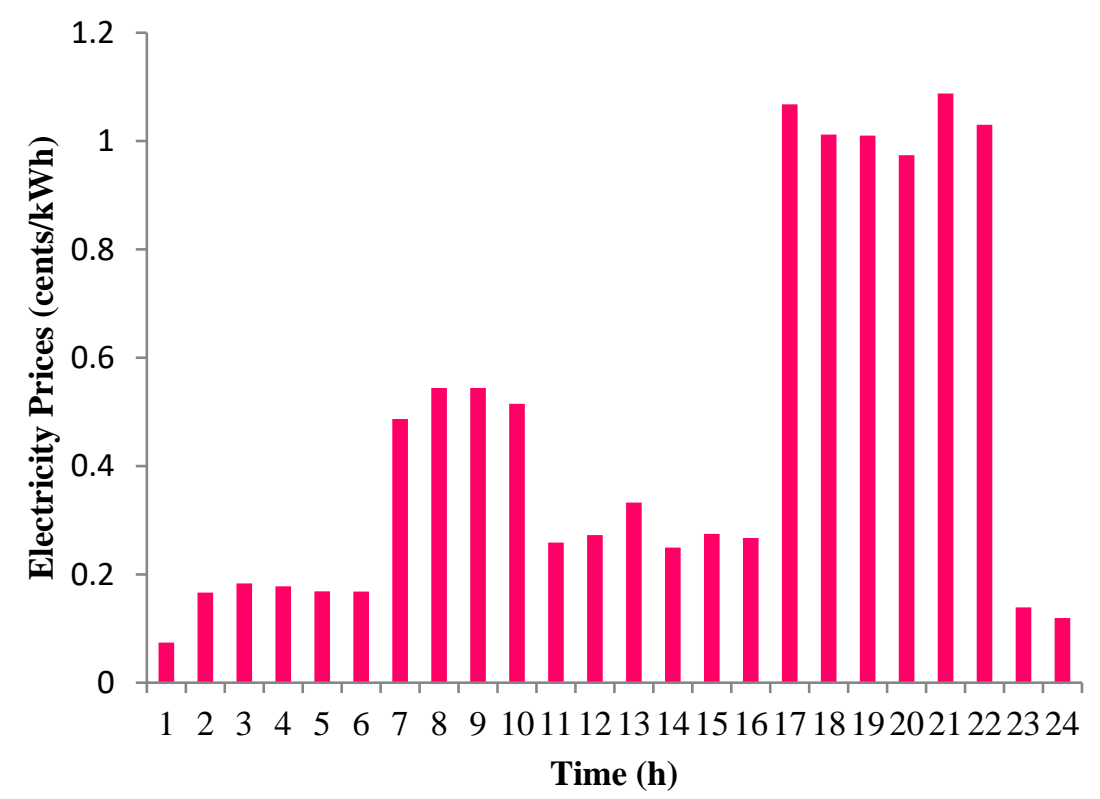

Figure 8. Predicted average electricity prices over a $24 \mathrm{~h}$ period.

\subsection{The Proposed Mathematical Modeling of a Smart Home}

In this section, the electrical smart home appliances with renewable energy sources (RESs), energy storage systems (ESS), and related mathematical parameters are analyzed in detail. The mathematical model contains different parts such as a photo-voltaic system, a small-scale windmill, smart battery, utility tariffs, home appliances, and their expenditure. Renewable energy is generated by the solar cells and windmill, that store it in a smart battery. Total local renewable energy generation is formulated by the given equation:

$$
\mathrm{P}^{\mathrm{B}}=\mathrm{p}^{\mathrm{S}}+\mathrm{p}^{\mathrm{W}}
$$


where $\mathrm{P}^{\mathrm{B}}$ is the battery power storage, and $\mathrm{P}^{\mathrm{S}}$ and $\mathrm{P}^{\mathrm{W}}$ denote the solar and wind power, respectively. Battery power is the sum of solar and wind power generation.

$$
\mathrm{P}^{\mathrm{ESS}}=\sum_{i=1}^{n} \mathrm{P}^{\mathrm{B}}=\sum\left(\mathrm{P}_{1}^{\mathrm{B}}+\mathrm{P}_{2}^{\mathrm{B}}+\mathrm{P}_{3}^{\mathrm{B}}+\mathrm{P}_{4}^{\mathrm{B}}+\ldots \ldots \ldots \ldots \ldots \ldots+\mathrm{P}^{\mathrm{B}}{ }_{-} \mathrm{N}\right)
$$

where $\mathrm{P}^{\mathrm{ESS}}$ is the power of energy storage system, which is equal to the individual sum of battery power storage, denoted by $\mathrm{P}^{\mathrm{B}}$, and $\mathrm{n}$ is the total number of batteries.

A single residential consumer with all home appliances power consumption is defined by the given equation:

$$
\mathrm{p}^{\mathrm{TA}}=\sum\left(\mathrm{p}^{\mathrm{L}}+\mathrm{p}^{\mathrm{WM}}+\mathrm{p}^{\mathrm{R}}+\mathrm{p}^{\mathrm{C}}+\mathrm{p}^{\mathrm{DW}}+\mathrm{p}^{\mathrm{H}}\right)
$$

where $\mathrm{P}^{\mathrm{TA}}$ denotes the total home appliances, $\mathrm{P}^{\mathrm{L}}$ indicates the lighting load, $\mathrm{P}^{\mathrm{WM}}$ illustrates the washing machine load, $\mathrm{P}^{\mathrm{R}}$ represents the refrigerator load, $\mathrm{P}^{\mathrm{C}}$ denotes computer power, $\mathrm{P}^{\mathrm{DW}}$ is the power taken by the dishwasher and $\mathrm{P}^{\mathrm{H}}$ is the heating load, respectively. All home users considered renewable energy as a primary source and utility as a secondary source. The user power demand is defined by Equation (11)

$$
\mathrm{p}^{\mathrm{U}}=\left(\mathrm{p}^{\mathrm{B}}+\mathrm{p}^{\mathrm{ESS}}\right)-\mathrm{p}^{\mathrm{TA}}
$$

where $\mathrm{p}^{\mathrm{U}}$ represents the user power, $\mathrm{p}^{\mathrm{B}}$ is the battery power and $\mathrm{p}^{\mathrm{ESS}}$ is the power of the energy storage systems. Similarly, $\mathrm{p}^{\mathrm{TA}}$ indicates the total home appliance's power of residential consumers. A home user's extra energy demand is met by the utility system and it is defined by the given Equation (12) and extra energy cost is formulated by Equation (13).

$$
\begin{gathered}
\mathrm{E}^{\mathrm{EE}}=\sum\left(\mathrm{p}^{\mathrm{UO}}-\mathrm{p}^{\mathrm{U}}\right) \\
\left.\mathrm{E}^{\mathrm{EEC}}=\sum\left(\left(\mathrm{p}^{\mathrm{UO}}-\mathrm{p}^{\mathrm{U}}\right) \times \mathrm{p}^{\mathrm{UP}}\right)\right)
\end{gathered}
$$

where $\mathrm{E}^{\mathrm{EE}}$ represents the extra energy, $\mathrm{p}^{\mathrm{UO}}$ is the utility power and $\mathrm{p}^{\mathrm{U}}$ is the user power. The user's extra energy is calculated by subtracting the user power from the utility operator. Similarly, $\mathrm{E}^{\mathrm{EEC}}$ defines the extra energy cost and $\mathrm{p}^{\mathrm{UP}}$ illustrates the utility price. A group of 20 home users are considered in the proposed community smart grid framework and the total user energy is given by Equation (14)

$$
\mathrm{E}^{\mathrm{TUE}}=\sum_{i=1}^{n} \mathrm{E}^{\mathrm{UE}}=\sum\left(\mathrm{E}_{1}^{\mathrm{U}}+\mathrm{E}_{2}^{\mathrm{U}}+\mathrm{E}_{3}^{\mathrm{U}}+\mathrm{E}_{4}^{\mathrm{U}}+\ldots \ldots \ldots \ldots \ldots \ldots+\mathrm{E}^{\mathrm{U} \_\mathrm{N}}\right)
$$

where $\mathrm{E}^{\mathrm{TUE}}$ represents the total user energy, $\mathrm{E}^{\mathrm{UE}}$ denotes the user energy and $\mathrm{E}^{\mathrm{U}}$ outlines the independent user energy consumption. The total user's energy cost is carried out by the given Equation (15)

$$
\mathrm{E}^{\mathrm{TUEC}}=\sum\left(\mathrm{E}_{1}^{\mathrm{U}}+\mathrm{E}^{\mathrm{U}}{ }_{2}+\mathrm{E}_{3}^{\mathrm{U}}+\mathrm{E}_{4}^{\mathrm{U}}+\ldots \ldots \ldots+\mathrm{E}^{\mathrm{U}} \mathrm{N}^{\mathrm{N}}\right) \times \mathrm{E}^{\mathrm{UC}}
$$

where $\mathrm{E}^{\mathrm{TUEC}}$ represents the total user energy cost and $\mathrm{E}^{\mathrm{UC}}$ denote the individual user energy cost. The total number of hours in a day is given by Equation (16).

$$
\mathrm{p}^{\mathrm{TNH}}=\sum_{\mathrm{i}=1}^{\mathrm{H}} \mathrm{P}^{\mathrm{H}}
$$

where $\mathrm{p}^{\mathrm{TNH}}$ represents the total number of hours and $\mathrm{p}^{\mathrm{H}}$ denote the hourly user power consumption. Total energy consumption and cost for a week is given by Equation (17)

$$
\mathrm{p}^{\mathrm{TND}}=\sum_{\mathrm{i}=1}^{\mathrm{D}} \mathrm{P}^{\mathrm{D}}
$$


where $\mathrm{p}^{\mathrm{TND}}$ represents the total number of day and $\mathrm{p}^{\mathrm{D}}$ denote the daily user power consumption. Total self-satisfied power demand are carried out by Equation (18)

$$
\mathrm{p}^{\mathrm{TSSPD}}=\sum \mathrm{p}^{\mathrm{SSPD}}
$$

In Equation (12), PTSSPD denotes the total self-satisfied power demand. Total number of energy clusters are carried out by Equation (19)

$$
\mathrm{p}^{\mathrm{TNEC}}=\sum \mathrm{p}^{\mathrm{EC}}=\sum\left(\mathrm{p}^{\mathrm{EC}}{ }_{1}+\mathrm{p}^{\mathrm{EC}}{ }_{2}+\mathrm{p}^{\mathrm{EC}}{ }_{3}\right)
$$

In Equation (19), $\mathrm{p}^{\mathrm{TNEC}}$ represents the total number of energy cluster whereas $\mathrm{p}^{\mathrm{EC}}$ denotes the power consumption of the independent energy cluster.

\subsection{Flow Chart of the Algorithm}

This section introduces a flow chart in Figure 9 to identify and explain the graphical overview of the energy allocation strategy to share and support user energy demand and simulation procedure.

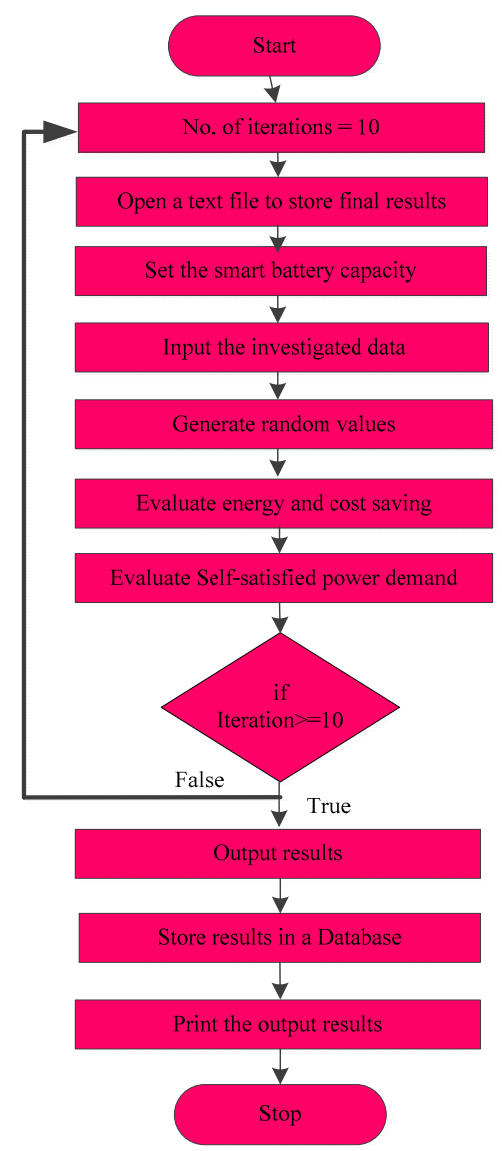

Figure 9. Algorithm Flowchart.

\subsection{The Proposed Algorithm}

In this section, the proposed algorithm for the community smart grid is documented. A precise and efficient algorithm is proposed which defines the step by step priority basis energy allocation and simulation execution process among the home uses in the community smart grid. The dynamic electricity prices are used for the simulation process. This may lead to complexity in solving it using conventional optimization problems. To solve this limitation, an efficient Energy Allocation Algorithm (EAA), shown the steps in Algorithm 1 and the flowchart in Figure 9, is designed. The EAA is used to 
optimize the new proposed cluster-based energy management system in the smart grid environment considering an ESS [39]. In this research, the EAA is also discussed effectively to share residential consumer's battery power and energy storage system within the energy cluster in the smart grid community. The prime objective of the proposed algorithm is to minimize the energy cost with a high level of customer satisfaction. Residential users consume most of the energy to meet household appliances' power demand. If a user's power consumption is greater than the rated capacity of the battery, then the battery requires charging up to the maximum level. If a healthy battery is found, then it is charged using the user's battery by sharing power. Otherwise, it continues to search to identify a healthy battery. Surplus energy selling is possible while RESs have sufficient power generation and after meeting user power demand.

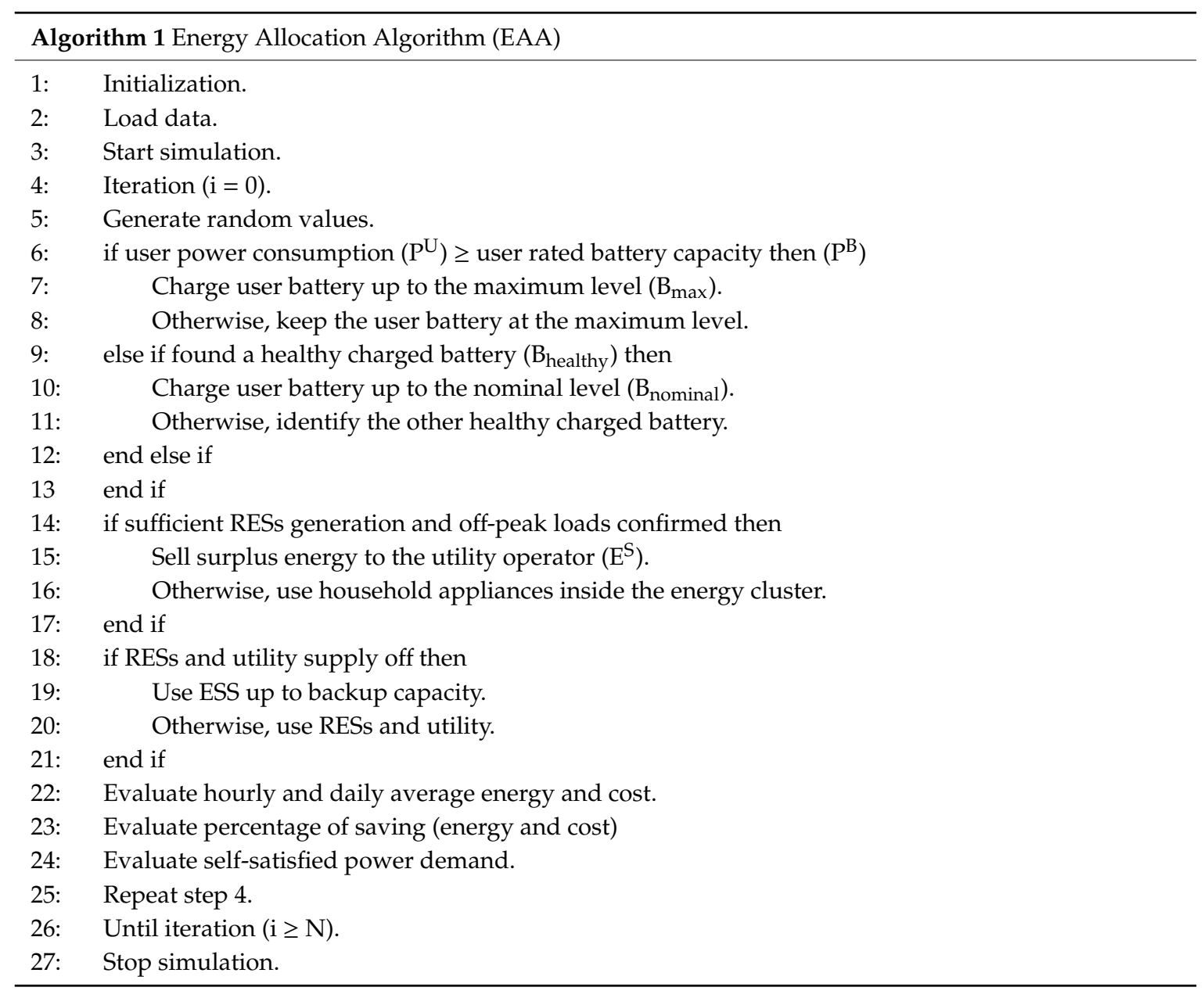

\section{Simulation Results}

The proposed energy management procedure and simulation results are outlined in this section to analyze and compare the effectiveness of the proposed REM scheme. A smart grid framework is taken into account in this research. Sufficient PV solar and wind power generation reduces the utility tariffs. An efficient energy allocation algorithm (EAA) is developed to manage residential consumer's smart battery power-sharing effectively.

In this work, an energy storage system (ESS) is considered in each energy cluster to support residential consumers while power demand appears. The capacity of the ESS is selected as $30 \mathrm{kWh}$, and the minimum and maximum energy storage margins are taken as 5 and $30 \mathrm{kWh}$, respectively. The primary energy level of the ESS is considered as $10 \mathrm{kWh}$. The smart grid constraints and the other input values are presented in Table 1 . The input data are picked from real-time investigations. However, 
those are slightly scaled up or down due to the precise application of this research. Three smart grid scenarios are considered, one existing and two proposed to compare the percentage of energy and cost savings. The simulation results are used to compare with the existing scenarios to show how the proposed scheme is better for reducing energy demand and cost significantly. It also evaluates the hourly and daily energy consumption and prices considering self-satisfied power demand to make the comparison effectively to propose an economic solution for residential consumers.

Table 1. Simulation parameters [25].

\begin{tabular}{lcc}
\hline \multicolumn{1}{c}{ Parameters } & Value & Unit \\
\hline PV generators & 125 & $\mathrm{~m}^{2}$ \\
Total covered area, A & 16 & $\%$ \\
Efficiency, $\eta_{\mathrm{s}}$ & 20 & $\mathrm{~kW}$ \\
Maximum power & 3 & $\mathrm{~m} / \mathrm{s}$ \\
Wind generators Cut-in velocity & 25 & $\mathrm{~m} / \mathrm{s}$ \\
Cut-out velocity & 10 & $\mathrm{~m} / \mathrm{s}$ \\
Rated speed & 20 & $\mathrm{~kW}$ \\
Maximum power & 10 & $\mathrm{kWh}$ \\
Battery initial level, BLo & 30 & $\mathrm{kWh}$ \\
Maximum energy level, BLmax & 5 & $\mathrm{kWh}$ \\
Minimum energy level, BLmin & 30 & $\mathrm{kWh}$ \\
Energy capacity & 3.5 & $\mathrm{kWh}$ \\
Maximum charging rate & 3.5 & $\mathrm{kWh}$ \\
Maximum discharging rate & 48 & $\mathrm{~h}$ \\
Total hour & 7 & $\mathrm{~d}$ \\
Total day & 20 & - \\
Total user & 10 & - \\
Total iteration & 0.072 & $€ / \mathrm{kWh}$ \\
Energy cost & &
\end{tabular}

\subsection{Case Study}

Several case studies are carried out to present the residential consumers' energy consumption patterns and cost comparison for economic solutions. A group of 20 residential consumers is considered through several energy clusters in the smart grid community to evaluate energy and cost through some case studies. In addition, three smart grid scenarios are considered, one existing and two proposed. In scenario 1, all residential consumers have power supply from the local utility only, whereas in scenario 2, all residential consumers have a power supply both from the local utility and RESs. Moreover, in scenario 3, all residential consumers have power supply from local utility, renewable energy sources (RESs) and, energy storage systems (ESS).

- Scenario1: the premises considering utility support only;

- Scenario 2: the premises considering utility support and RESs;

- Scenario 3: the premises considering utility support, RESs and ESS.

\subsubsection{Case Study I}

In this method, residential consumers receive power from the utility grid. There are no renewable energy sources (RESs) and energy storage systems (ESS). This approach is completely unable to manage economic issues and energy minimization due to the absence of RESs and ESS. All residential appliances receive energy from the utility system and the user pays the utility bills after a certain period. Energy consumption and electricity cost management for three scenarios over a $48 \mathrm{~h}$ time period are illustrated in Figure 10. In this research, scenario 1 is considered as existing, whereas scenario 2 and scenario 3 are the proposed energy management method. 
Residential consumers have different load patterns such as peak-load, off-peak and mid-peak loads. The load profiles are presented in Figures 5-7. To optimize energy consumption and cost, it is necessary to take some efficient initiatives and techniques.

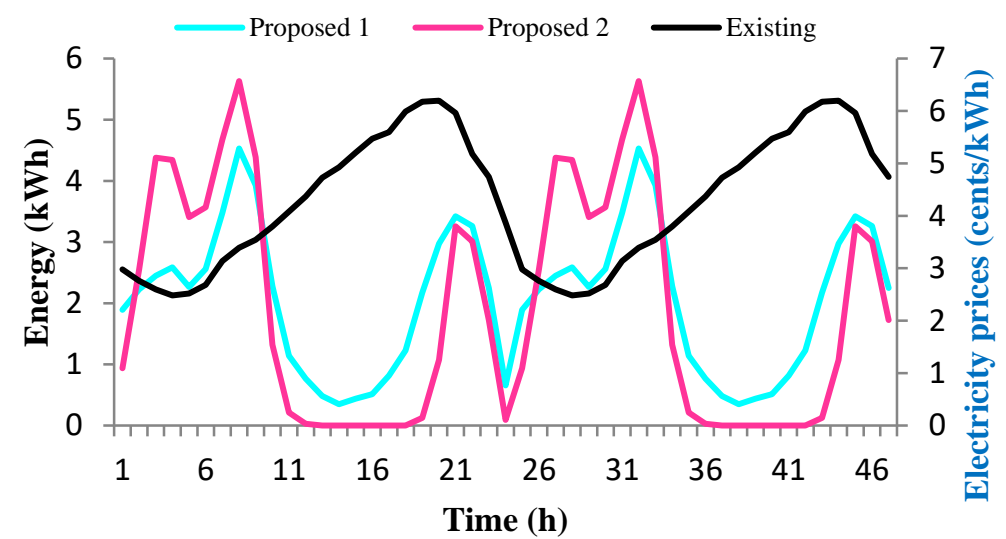

Figure 10. Comparison of energy and cost between proposed and existing scenario over $48 \mathrm{~h}$ time period.

\subsubsection{Case Study II}

The comparison between the proposed 1 and existing scenarios with a cost management scheme over a $48 \mathrm{~h}$ time period is presented in Figure 11 and tabulated in Table 2. The existing scenario has only local utility support, and thus the total utility cost is 7.02 EUR. On the other hand, the proposed 1 scenario has local utility and RES support, thus the electricity cost is $3.90 \mathrm{EUR}$, which is $45 \%$ less than the existing approach.

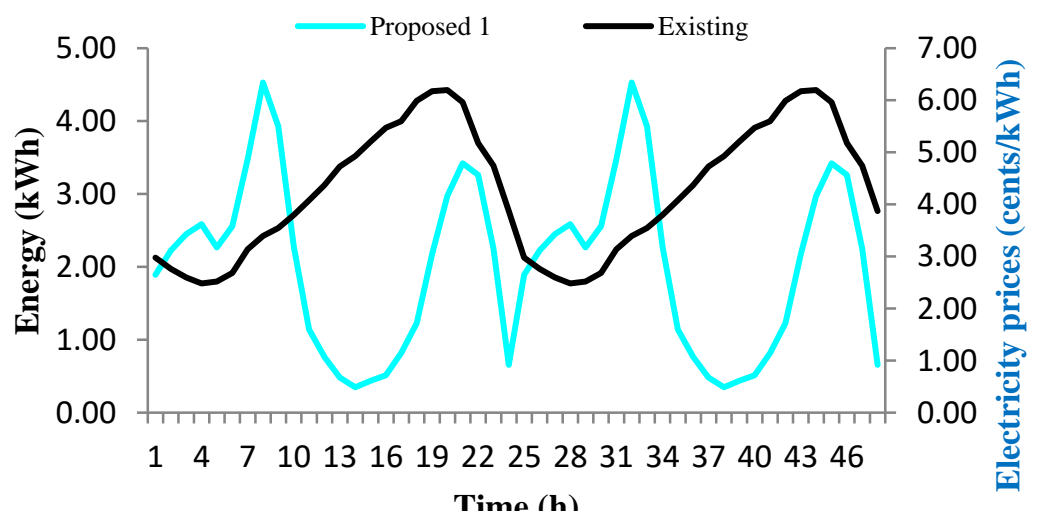

Time (h)

Figure 11. Comparison of energy and cost saving between the proposed 1 and existing scenarios over $48 \mathrm{~h}$ time period.

Table 2. Percentage of energy and cost saving between the proposed 1 and existing scenarios for case II.

\begin{tabular}{cccc}
\hline Scenarios & Energy (kWh) & Cost (EUR) & \%Saving \\
\hline Existing & 90 & 7.02 & 0 \\
Proposed 1 & 50 & 3.90 & 45 \\
\hline
\end{tabular}

\subsubsection{Case Study III}

The comparison between proposed 2 and existing scenario with a cost management scheme over a $48 \mathrm{~h}$ time period is illustrated in Figure 12 and presented in Table 3. The existing scenario has only local utility support, thus the total utility cost is 7.02 EUR. On the other hand, the proposed 2 scenario has local utility, RES and ESS support, thus the electricity cost is 3.12 EUR, which is $56 \%$ less than the 
existing scenario. ESS is charged from the utility grid during low energy cost hours and discharged during high price hours.

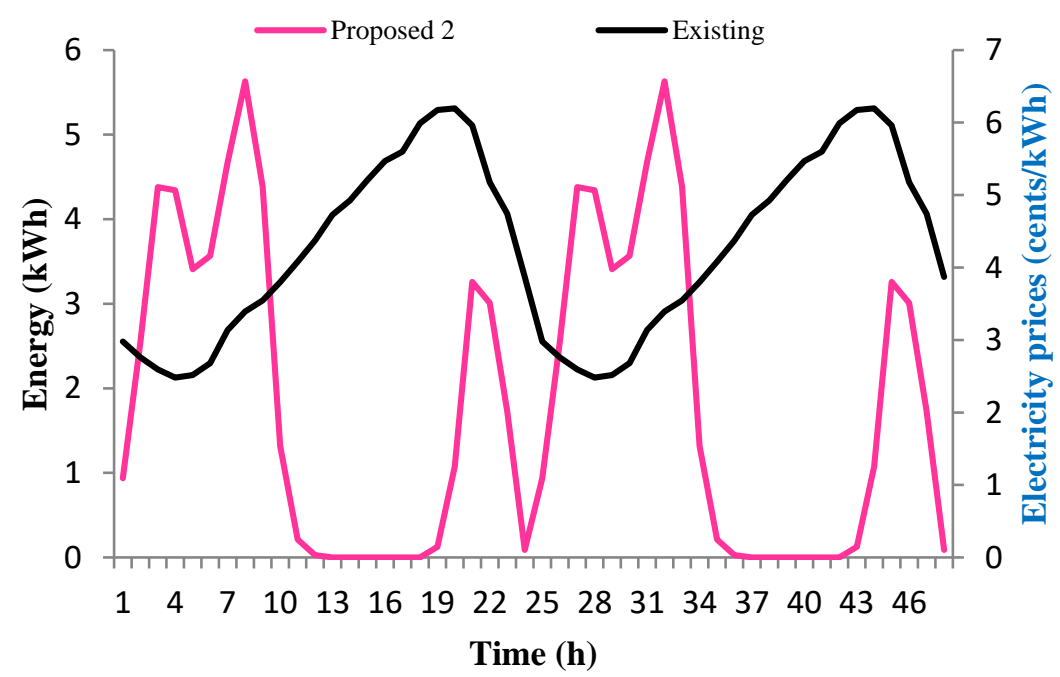

Figure 12. Comparison of energy and cost saving between the proposed 2 and existing scenarios over $48 \mathrm{~h}$ time period.

Table 3. Percentage of energy and cost saving between the proposed 2 and existing scenarios for case III.

\begin{tabular}{cccc}
\hline Scenarios & Energy (kWh) & Cost (EUR) & \%Saving \\
\hline Existing & 90 & 7.02 & 0 \\
Proposed 2 & 40 & 3.12 & 56 \\
\hline
\end{tabular}

\subsection{Discussion}

In this section, the overall energy and cost minimization for residential consumers is outlined based on several case studies. Case I is completely unable to minimize energy and monetary cost due to the absence of alternative sources of energy and energy storage systems (ESS). However, case II and case III can save a significant amount of energy and cost considering renewable energy sources (RESs), energy storage systems (ESS), and self-satisfied power demand. The percentage of savings is tabulated in Table 4 to identify the most profitable case.

Table 4. Comparison of the proposed and existing energy, and cost management within case I, II, and III.

\begin{tabular}{cccc}
\hline Cases & Energy (kWh) & Cost (EUR) & \%Saving \\
\hline Case I & 90 & 7.02 & 0 \\
Case II & 50 & 3.90 & 45 \\
Case III & 40 & 3.12 & 56 \\
\hline
\end{tabular}

Figure 13 presents the percentage of energy savings management within different case studies over a $48 \mathrm{~h}$ time period. Case II can save $45 \%$ of the energy consumption, whereas case III can save $56 \%$. 


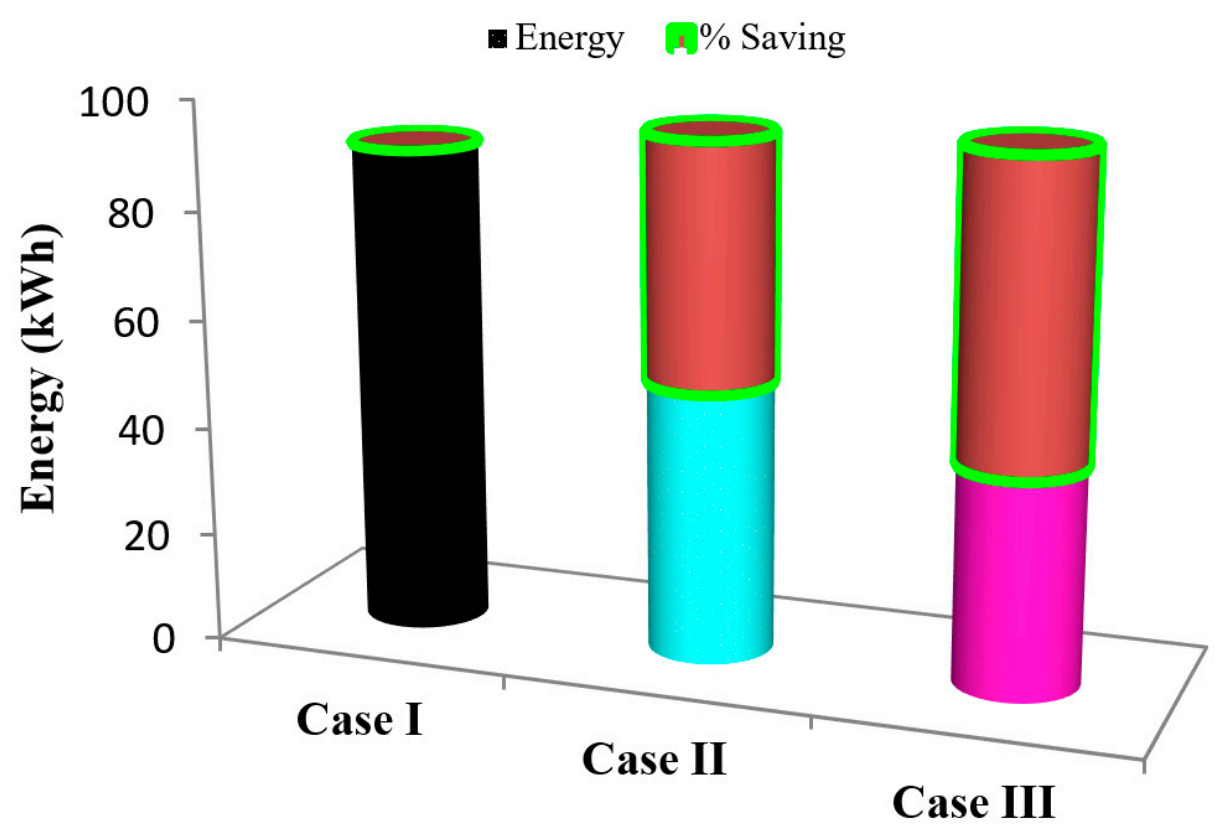

Figure 13. Percentage of energy savings management for 20 users within case-I, II, and III over $48 \mathrm{~h}$ time period.

The green line in Figure 13 indicates the percentage of energy savings, which is sharply increasing due to cost-effective energy management. On the other hand, Figure 14 illustrates the percentage of monetary cost savings management within different case studies over the $48 \mathrm{~h}$ time period, which is linearly increasing due to the proposed economic energy optimization algorithm.

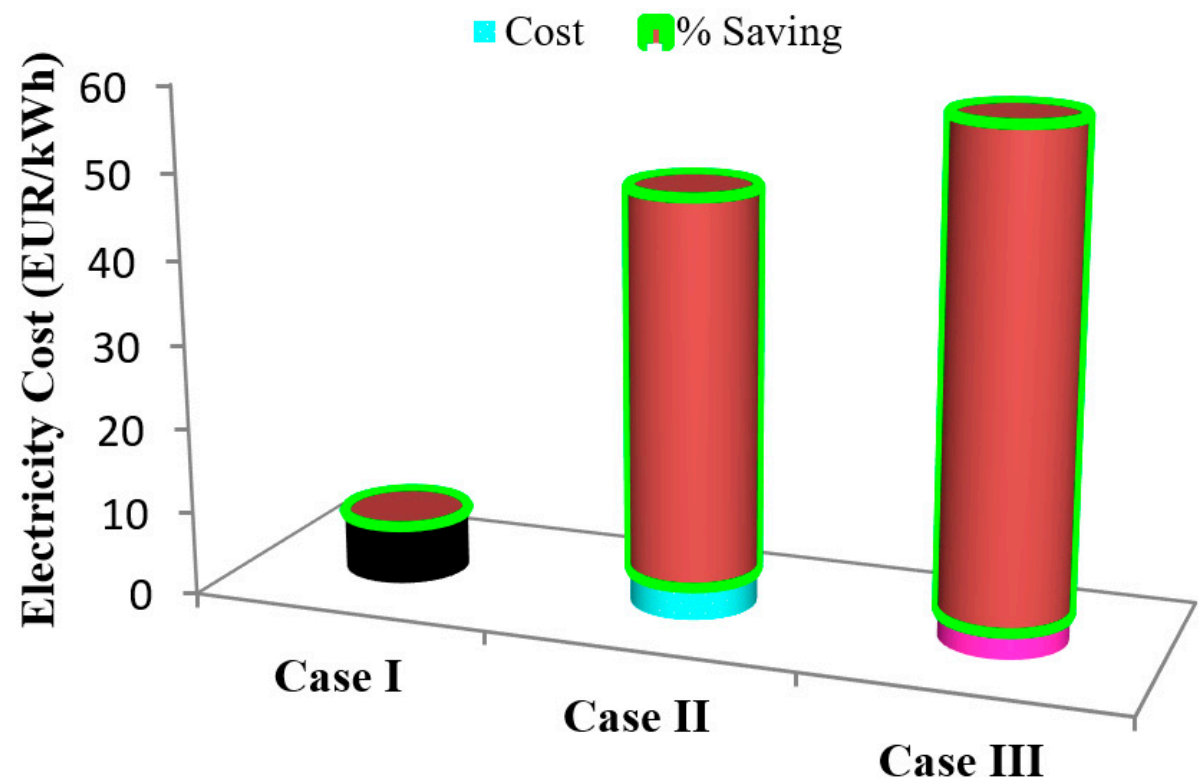

Figure 14. Percentage of cost savings management for 20 users within case I, II, and III over $48 \mathrm{~h}$ time period.

The comparison of average daily energy consumption and cost management within three different cases is presented in Figure 15 and tabulated in Table 5. From Figure 15, the daily energy consumption is the greatest in case I, whereas in case II and case III the consumption is declining. Evaluating several case studies, the overall energy and cost reduction are profitably accelerated in case II and case III due to the inclusion of RES and ESS with the proposed energy allocation algorithm (EAA) in the smart grid environment. To get dual supply opportunity, an on-grid tied smart grid system is considered. 
Table 5. Comparison of the average daily energy consumption and cost management within three cases.

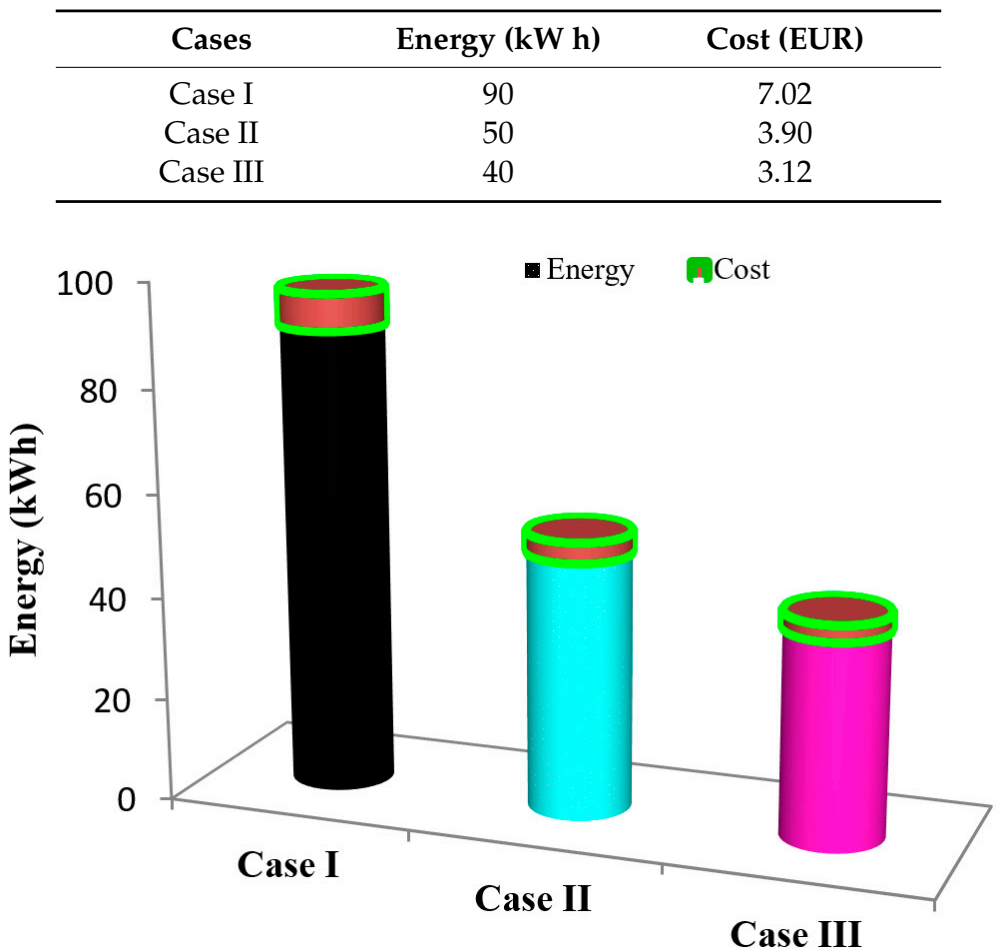

Figure 15. Comparison of average daily energy consumption and cost management for 20 users within cases I, II, and III.

\subsubsection{Energy and Cost Savings for Single Premises}

A comparison of energy consumption and cost for a single residential consumer in a day is illustrated in Figure 16 and Table 6 to get a basic idea regarding energy and the respective cost within different scenarios. Residential consumers consume most of their electrical energy through household appliances such as lights, fans, computers, washing machines, dishwashers, coffee makers, and so on. The highest energy consumption is shown in scenario 1 due to it having local utility support only. Meanwhile, the lowest energy consumption is attained by scenario 3 because of utility supply, RESs, and ESS integration. Solar and wind generators produce electricity while sufficient solar irradiation and wind velocity are available, respectively. The generated energy is stored in a smart battery to use and share among residential consumers when peak load or extra demand appears. Meanwhile, a consumer can mitigate their peak load demand using RESs and ESS as self-satisfied power demand instead of using the utility supply. The application of ESS in the smart grid community through energy clusters is very essential due to the lack of power generation by RESs.

Table 6. Comparison of the average daily energy consumption and cost management for a single user within three scenarios.

\begin{tabular}{ccc}
\hline Scenarios & Energy (kW h) & Cost (EUR) \\
\hline Scenario 1 & 4.50 & 0.35 \\
Scenario 2 & 2.50 & 0.19 \\
Scenario 3 & 2.00 & 0.15 \\
\hline
\end{tabular}

During the winter season and cloudy weather, ESS can effectively support the residential consumers to reduce peak demand and utility tariffs. This ESS energy is efficiently managed with the proposed EAA among the community smart grid users. ESS charges during low utility cost hours and discharges 
while there is a peak load and higher electricity rates. These strategies reduce the system operating cost as well as the energy cost.

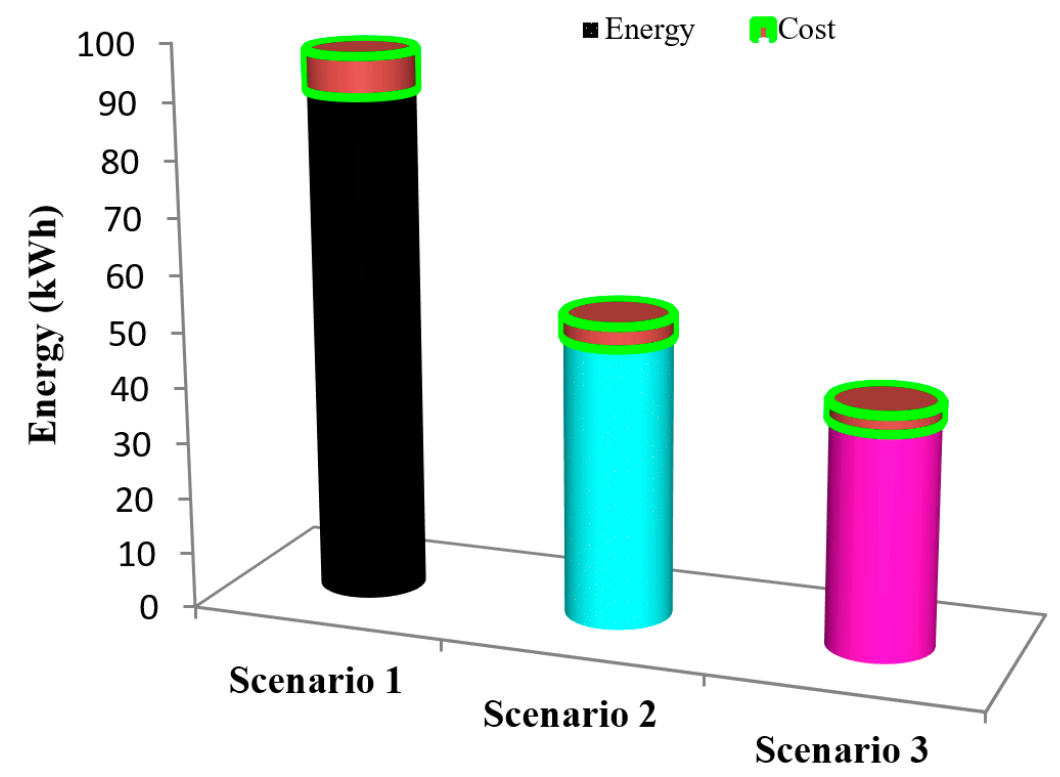

Figure 16. Comparison of the average daily energy and cost management for a single user within three scenarios.

\subsubsection{Self-Satisfied Power Demand}

The main functionality of this strategy is user power sharing within the community smart grid. Each user can share a maximum $50 \%$ of the power of his rated capacity so that the user is capable to meet its own demand; thus, this strategy helps to reduce the dependency of the user on fossil fuel-based energy, which endorses a sustainable solution. A comparison of the proposed and existing self-satisfied power demand between an existing and proposed scenario with proposed EAA is illustrated in Figure 17 and tabulated in Table 7. In Figure 18, the green line indicates the percentage of self-satisfied power demand savings, which is $20 \%$ and $30 \%$, respectively. The proposed 2 method has $10 \%$ more self-satisfied power demand savings than the proposed 1 method, due to ESS integration. However, proposed 2 has 30\% more savings than the existing scenario because of RESs and ESS integration with the local utility supply.

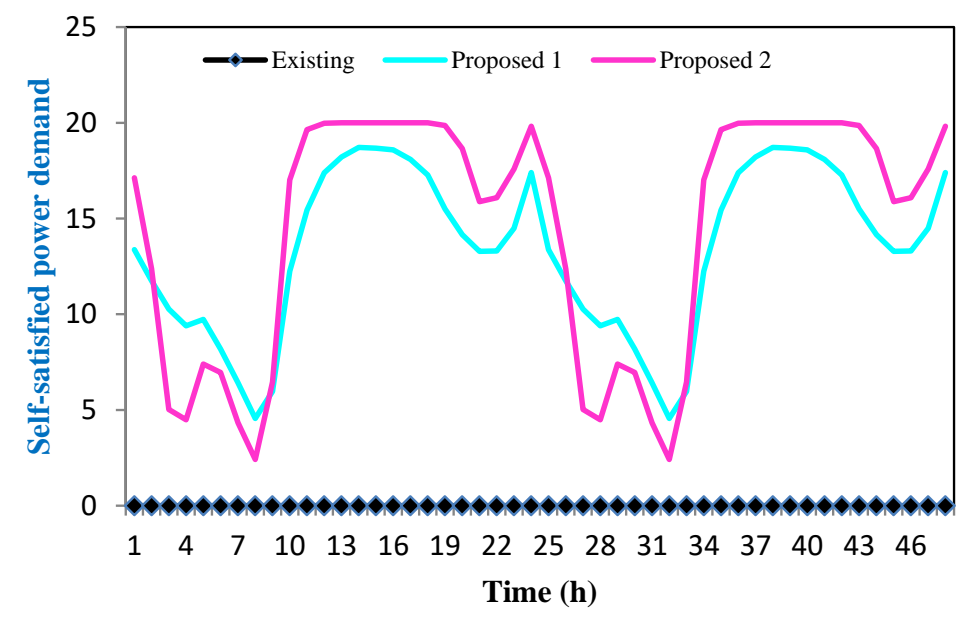

Figure 17. Comparison of self- satisfied power demand between existing and proposed scenarios over $48 \mathrm{~h}$ time period. 
Table 7. Comparison of self- satisfied power demand between existing and proposed scenarios over $48 \mathrm{~h}$ time period.

\begin{tabular}{ccc}
\hline Scenarios & Self-Satisfied Power Demand & \%Saving \\
\hline Existing & 0 & 0 \\
Proposed 1 & 16 & 20 \\
Proposed 2 & 20 & 30 \\
\hline
\end{tabular}

The prescribed savings are only possible while RESs can generate sufficient power and ESS can charge at a maximum level from the local utility supply when there is low energy cost. Moreover, Figure 18 demonstrates the percentage of self-satisfied power demand saving within existing and proposed scenarios over a $48 \mathrm{~h}$ time period. The green line indicates the percentage of savings which is sharply increased to address economic benefits.

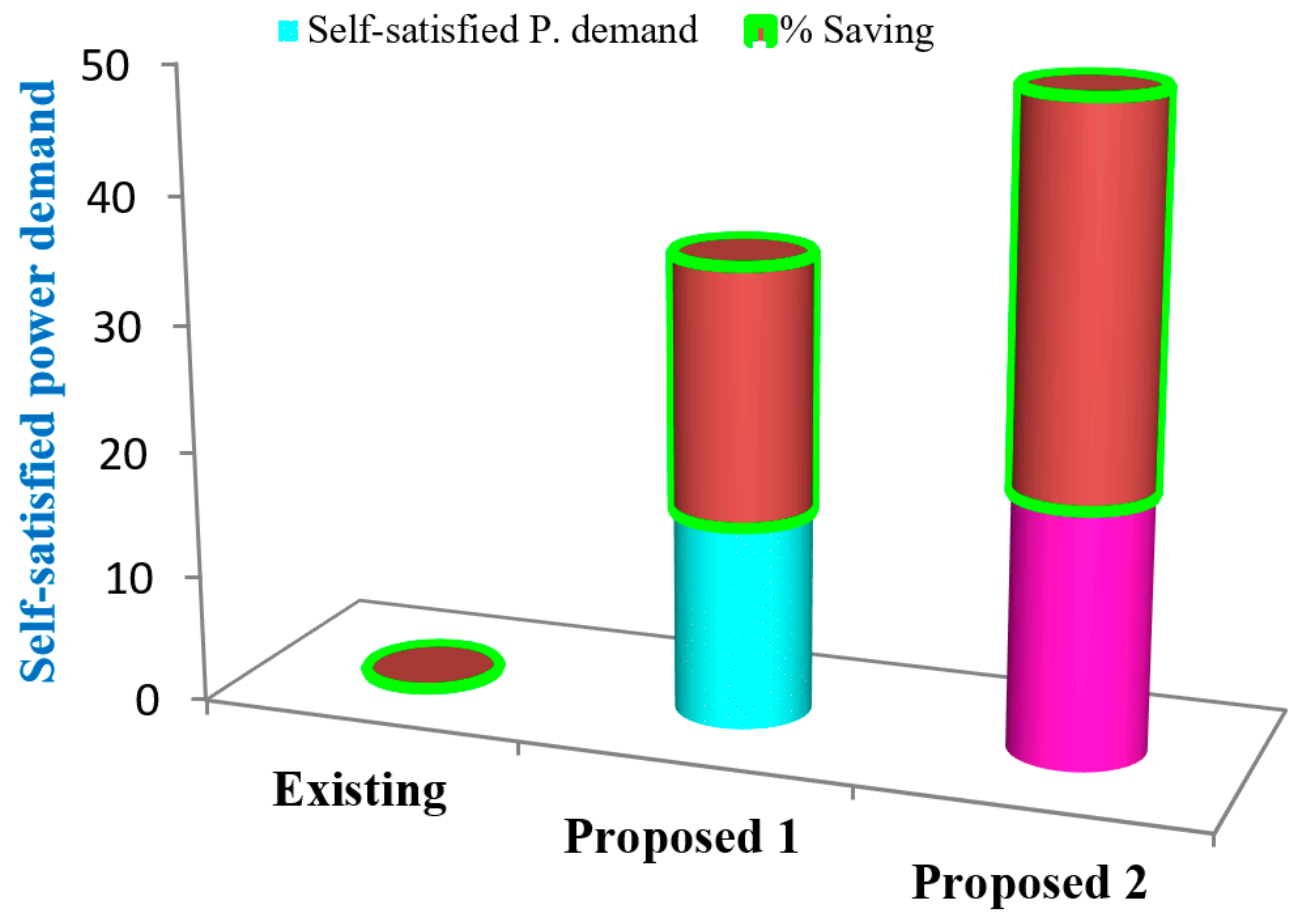

Figure 18. Percentage of self-satisfied power demand saving within existing and proposed scenarios over $48 \mathrm{~h}$ time period.

\subsubsection{Limitations of the Proposed Method}

The proposed methods have some limitations due to the uncertainty of solar and wind power generation and the limited capacity of the energy storage system (ESS). The uncertainty modelling for solar and wind systems can be done with different stochastic methods. A comprehensive study on several existing uncertainty modelling can be conducted and incorporated in the proposed EAA as future work. Furthermore, optimal size and locations of ESS and RESs considering large smart grid networks can be further studied which have not been considered in this study.

\subsubsection{Case Comparison}

By summing up all other information and comparing different case studies, the most cost-effective method is achieved in this work. In case I, residential consumers have fixed utility tariffs and a nominated $\mathrm{kW}$ demand. Thus, the consumer cannot exceed the allocated energy demand which is set by the utility operator. For this reason, the consumer cannot avoid the peak load and higher utility tariffs. To overcome these difficulties, case II demonstrated an excellent idea by installing RESs with 
a utility grid to mitigate the peak load and higher utility costs. However, it is not always possible due to the dependency on solar irradiation and wind velocity during cloudy weather and the winter season. Case III accelerates the percentage of energy and cost-saving by $11 \%$ compared to case II, which is an added advantage for the consumers.

Finally, case III has additional energy storage systems (ESS) with case II to eliminate the mentioned difficulties which are represented in Figure 19. The ESS charges during low energy cost periods and discharges when peak load and extra demand arise. The compared amount is not much higher due to the moderate size of ESS. However, installing a large ESS requires a big battery bank, leading greater energy costs which consumers may not support.

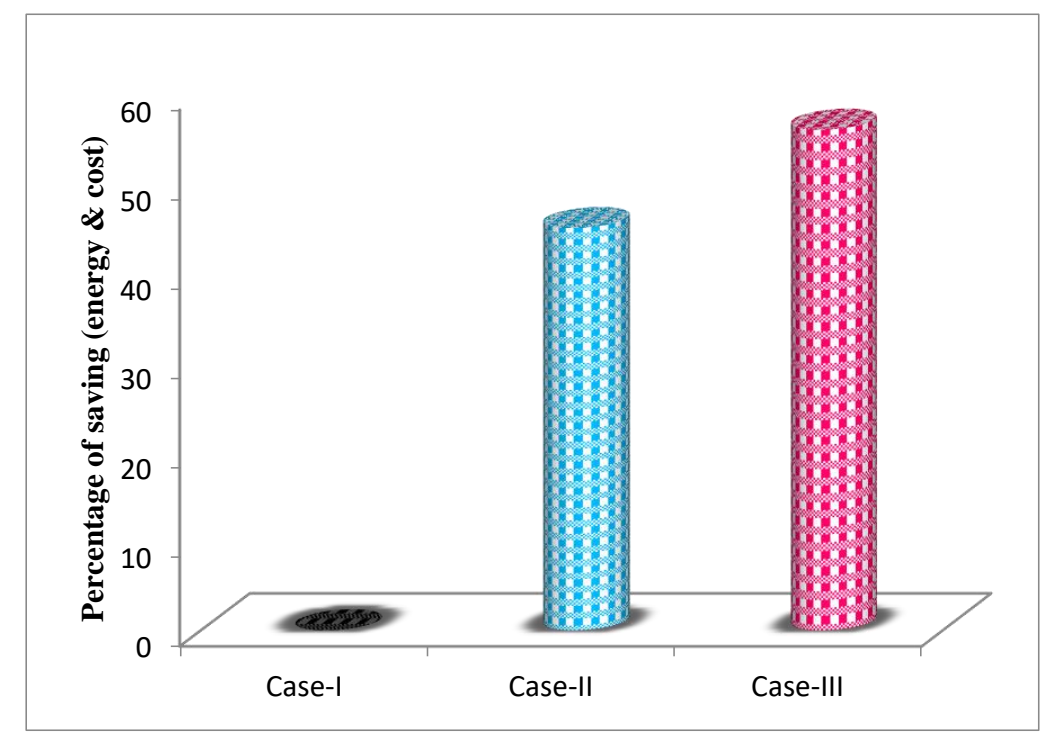

Figure 19. Comparison of the percentage of energy and cost saving for cases I, II and III.

We have found that the initial investment for RESs and ESS is a cost-effective and sustainable point of view. A depreciation cost is considered with RESs and ESS to make the proposed model more realistic. Governments and many energy suppliers are encouraged to provide home loans to residential consumers for installing a small-scale renewable energy generator. This may be a flexible opportunity for the low-income bracket individuals and mid category consumers. The proposed model can be implemented effectively in a small-scale micro-grid environment.

\section{Conclusions}

The development of a cluster-based energy management scheme for the residential applicants in the smart grid framework with renewable energy sources (RESs), an energy storage system (ESS), and self-satisfied power demand is proposed in this paper for a group of residential consumers. The residential energy management (REM) problem with consumer's energy consumption and cost minimization is modeled. A real-time tariff scheme is considered to implement the proposed REM model. An efficient energy allocation algorithm (EAA) considering ESS charging and discharging limits, RESs availability, consumers' load profile, and utility supply is developed. The offered model and EAA are implemented in a practical system considering twenty residential consumers. The benefits of the proposed REM scheme and ESS are investigated with three different scenarios. Finally, the economic analysis for three approaches with RESs, ESS, and self-satisfied power demand is also done in this paper with the help of the $\mathrm{C}++$ simulation tool. The proposed schemes save energy and cost by up to $45 \%$ and $56 \%$ compared to the existing methods, as evident from the simulation results. The results also outline that the offered method can save the self-satisfied power demand by up to $20 \%$ and $30 \%$, respectively, while sufficient RESs and ESS are available. From the overall analysis, the proposed REM model can enhance the benefits with the RESs and ESS integration. Moreover, the simulation outcomes 
prove the potential benefits of residential consumers and endorse the green effort to improve the power management infrastructure's sustainability and effectiveness.

Author Contributions: M.M.U.R., F.G., M.A.H. and M.S.A. initiated the idea, designed the cluster-based energy management scheme and drafted the article. M.M.U.R., F.S.A.-I., R.S. performed the simulations and formal analysis. All authors made revisions of the articles. All authors have read and agreed to the published version of the manuscript.

Funding: This research received no external funding.

Conflicts of Interest: Authors have no conflict of interest.

\section{Nomenclature}

\begin{tabular}{|c|c|}
\hline SG & smart grid \\
\hline SM & smart meter \\
\hline REM & residence energy management \\
\hline DSM & demand-side management \\
\hline HEM & home energy management \\
\hline EAA & energy allocation algorithm \\
\hline HANs & home area networks \\
\hline RESs & renewable energy sources \\
\hline ESS & energy storage system \\
\hline SI & solar irradiation \\
\hline PV & photovoltaic \\
\hline PwT & total wind power \\
\hline PsT & total solar power \\
\hline BLo & initial battery energy level \\
\hline BLmax & maximum battery energy level \\
\hline BLmin & minimum battery energy level \\
\hline $\mathrm{P}^{\mathrm{B}}$ & battery power \\
\hline $\mathrm{P}^{\mathrm{S}}$ & solar power \\
\hline $\mathrm{p}^{\mathrm{W}}$ & wind power \\
\hline $\mathrm{p}^{\text {THA }}$ & power of total home appliances \\
\hline $\mathrm{p}^{\mathrm{L}}$ & lighting load \\
\hline $\mathrm{pWM}$ & washing machine power \\
\hline $\mathrm{pR}$ & refrigerator power \\
\hline $\mathrm{pC}$ & computer power \\
\hline $\mathrm{pDW}$ & dishwasher power \\
\hline $\mathrm{pH}$ & power taken by a heater \\
\hline PESS & energy storage systems \\
\hline EEE & users extra energy \\
\hline EEEC & users extra energy cost \\
\hline pUO & utility operator \\
\hline pUP & utility price \\
\hline pTNC & total number of community \\
\hline pTNU & total number of users \\
\hline ETUE & total users energy \\
\hline ETUEC & total users energy cost \\
\hline pTNH & total number of hours \\
\hline pTND & total number of days \\
\hline pTSSPD & total self-sat. power demand \\
\hline pTNI & total number of iteration \\
\hline $\mathrm{pCE}$ & cost of energy \\
\hline $\mathrm{pCSB}$ & the capacity of smart battery \\
\hline pTNEC & total num. of energy cluster \\
\hline
\end{tabular}




\section{References}

1. Vincent, R.; Houari, A.; Ait-Ahmed, M.; Benkhoris, M.F. Influence of different time period-based battery energy management strategies on residential microgrid profitability. J. Energy Storage 2020, 29, 101340. [CrossRef]

2. Rashid, M.M.U.; Granelli, F.; Hossain, M.A.; Alam, M.S.; Al-Ismail, F.S.; Karmaker, A.K.; Rahaman, M.M. Development of Home Energy Management Scheme for a Smart Grid Community. Energies 2020, $13,4288$. [CrossRef]

3. Javaid, N.; Naseem, M.; Rasheed, M.B.; Mahmood, D.; Khan, S.A.; Alrajeh, N.; Iqbal, Z. A new heuristically optimized Home Energy Management controller for smart grid. Sustain. Cities Soc. 2017, 34, $211-227$. [CrossRef]

4. Siano, P.; Sarno, D.; Straccia, L.; Marrazzo, A.T. A novel method for evaluating the impact of residential demand response in a real time distribution energy market. J. Ambient Intell. Humaniz. Comput. 2016, 7, 533-545. [CrossRef]

5. Karmaker, A.K.; Rahman, M.M.; Hossain, M.A.; Ahmed, M.R. Exploration and corrective measures of greenhouse gas emission from fossil fuel power stations for Bangladesh. J. Clean. Prod. 2020, 244, 118645. [CrossRef]

6. Guo, Y.; Pan, M.; Fang, Y. Optimal power management of residential customers in the smart grid. IEEE Trans. Parallel Distrib. Syst. 2012, 23, 1593-1606. [CrossRef]

7. Agnetis, A.; De Pascale, G.; Detti, P.; Vicino, A. Load scheduling for household energy consumption optimization. IEEE Trans. Smart Grid 2013, 4, 2364-2373. [CrossRef]

8. Basso, T.S.; DeBlasio, R. IEEE 1547 series of standards: Interconnection issues. IEEE Trans. Power Electron. 2004, 19, 1159-1162. [CrossRef]

9. Abushnaf, J.; Rassau, A.; Górnisiewicz, W. Impact of dynamic energy pricing schemes on a novel multi-user home energy management system. Electr. Power Syst. Res. 2015. [CrossRef]

10. Sousa, T.; Lezama, F.; Soares, J.; Ramos, S.; Vale, Z. A Flexibility Home Energy Management System to Support Agreggator Requests in Smart Grids. In Proceedings of the 2018 IEEE Symposium Series on Computational Intelligence (SSCI), Piscataway, NJ, USA, 31 January 2019; pp. 1830-1836.

11. Cherukuri, S.H.C.; Saravanan, B. Hybrid energy management strategy for residential consumers using virtual and actual storage systems. J. Energy Storage 2019, 25, 100894. [CrossRef]

12. Chamandoust, H.; Derakhshan, G.; Hakimi, S.M.; Bahramara, S. Tri-objective scheduling of residential smart electrical distribution grids with optimal joint of responsive loads with renewable energy sources. J. Energy Storage 2020, 27, 101112. [CrossRef]

13. Falabretti, D.; Lindholm, M.; Merlo, M.; Scapeccia, G. Energy storage coupling in a high efficiency household scenario: A real life experimental application. J. Energy Storage 2018, 17, 496-506. [CrossRef]

14. Lobaccaro, G.; Carlucci, S.; Löfström, E. A Review of Systems and Technologies for Smart Homes and Smart Grids. Energies 2016, 9, 348. [CrossRef]

15. Wright, C.; Baur, S.; Grantham, K.; Stone, R.B.; Grasman, S.E. Residential Energy Performance Metrics. Energies 2010, 3, 1194-1211. [CrossRef]

16. Pawar, P.; Vittal K, P. Design and development of advanced smart energy management system integrated with IoT framework in smart grid environment. J. Energy Storage 2019, 25, 100846. [CrossRef]

17. Karmaker, A.K.; Ahmed, M.R.; Hossain, M.A.; Sikder, M.M. Feasibility assessment \& design of hybrid renewable energy based electric vehicle charging station in Bangladesh. Sustain. Cities Soc. 2018, 39, $189-202$. [CrossRef]

18. Sperstad, I.; Korpås, M. Energy Storage Scheduling in Distribution Systems Considering Wind and Photovoltaic Generation Uncertainties. Energies 2019, 12, 1231. [CrossRef]

19. Carli, R.; Dotoli, M.; Jantzen, J.; Kristensen, M.; Ben Othman, S. Energy scheduling of a smart microgrid with shared photovoltaic panels and storage: The case of the Ballen marina in Samsø. Energy 2020, 198, 117188. [CrossRef]

20. Ziadi, Z.; Taira, S.; Oshiro, M.; Funabashi, T. Optimal power scheduling for smart grids considering controllable loads and high penetration of photovoltaic generation. IEEE Trans. Smart Grid 2014, 5, 2350-2359. [CrossRef] 
21. Silva, B.N.; Khan, M.; Han, K. Futuristic Sustainable Energy Management in Smart Environments: A Review of Peak Load Shaving and Demand Response Strategies, Challenges, and Opportunities. Sustainability 2020, 12, 5561. [CrossRef]

22. Zhou, B.; Li, W.; Chan, K.W.; Cao, Y.; Kuang, Y.; Liu, X.; Wang, X. Smart home energy management systems: Concept, configurations, and scheduling strategies. Renew. Sustain. Energy Rev. 2016, 61, 30-40. [CrossRef]

23. Tsui, K.M.; Chan, S.C. Demand response optimization for smart home scheduling under real-time pricing. IEEE Trans. Smart Grid 2012, 3, 1812-1821. [CrossRef]

24. Bui, V.H.; Hussain, A.; Kim, H.M. A multiagent-based hierarchical energy management strategy for multi-microgrids considering adjustable power and demand response. IEEE Trans. Smart Grid 2018, 9, 1323-1333. [CrossRef]

25. Hossain, M.A.; Pota, H.R.; Squartini, S.; Abdou, A.F. Modified PSO algorithm for real-time energy management in grid-connected microgrids. Renew. Energy 2019. [CrossRef]

26. Alam, M.S.; Abido, M.A.Y.; El-Amin, I. Fault Current Limiters in Power Systems: A Comprehensive Review. Energies 2018, 11, 1025. [CrossRef]

27. Sattarpour, T.; Nazarpour, D.; Golshannavaz, S. A multi-objective HEM strategy for smart home energy scheduling: A collaborative approach to support microgrid operation. Sustain. Cities Soc. 2018, 37, 26-33. [CrossRef]

28. Khalifa, T.; Naik, K.; Alsabaan, M.; Nayak, A. A transport control protocol suite for smart metering infrastructure. In Proceedings of the 2011 International Conference on Electronic Devices, Systems, and Applications, Kuala Lumpur, Malaysia, 25-27 April 2011; pp. 5-10.

29. Zipperer, A.; Aloise-Young, P.A.; Suryanarayanan, S.; Roche, R.; Earle, L.; Christensen, D.; Bauleo, P.; Zimmerle, D. Electric energy management in the smart home: Perspectives on enabling technologies and consumer behavior. Proc. IEEE 2013, 101, 2397-2408. [CrossRef]

30. United States Government Accountability Office. GAO-11-117 Electricity Grid Modernization: Progress Being Made on Cybersecurity Guidelines, but Key Challenges Remain to Be Addressed; GAO: Washington, DC, USA, 2011.

31. FitzPatrick, G.J.; Wollman, D.A. NIST interoperability framework and action plans. In Proceedings of the IEEE PES General Meeting, PES 2010, Providence, RI, USA, 25-29 July 2010.

32. Ur Rashid, M.M.; Hasan, M.M. Simulation based energy and cost optimization for home users in a community smart grid. Int. J. Renew. Energy Res. 2018, 8, 1281-1287.

33. Justus, C.G. Wind energy statistics for large arrays of wind turbines (New England and Central U.S. Regions). Sol. Energy 1978, 20, 379-386. [CrossRef]

34. Rehman, S.; Al-Abbadi, N.M. Wind shear coefficients and energy yield for Dhahran, Saudi Arabia. Renew. Energy 2007, 32, 738-749. [CrossRef]

35. Borowy, B.S.; Salameh, Z.M. Optimum Photovoltaic Array Size for a Hybrid Wind/PV System. IEEE Trans. Energy Convers. 1994, 9, 482-488. [CrossRef]

36. Farrugia, R.N. The wind shear exponent in a Mediterranean island climate. Renew. Energy 2003, 28, 647-653. [CrossRef]

37. Xiao, W.; Lind, M.G.J.; Dunford, W.G.; Capel, A. Real-time identification of optimal operating points in photovoltaic power systems. IEEE Trans. Ind. Electron. 2006, 53, 1017-1026. [CrossRef]

38. Kaabeche, A.; Belhamel, M.; Ibtiouen, R. Sizing optimization of grid-independent hybrid photovoltaic/wind power generation system. Energy 2011, 36, 1214-1222. [CrossRef]

39. Mohsenian-Rad, A.H.; Wong, V.W.S.; Jatskevich, J.; Schober, R. Optimal and autonomous incentive-based energy consumption scheduling algorithm for smart grid. In Proceedings of the Innovative Smart Grid Technologies Conference, ISGT 2010, Gothenburg, Sweden, 11-13 October 2010.

(C) 2020 by the authors. Licensee MDPI, Basel, Switzerland. This article is an open access article distributed under the terms and conditions of the Creative Commons Attribution (CC BY) license (http://creativecommons.org/licenses/by/4.0/). 